\title{
Plate tectonics conserves angular momentum
}

\author{
C. Bowin \\ Department of Geology \& Geophysics, Woods Hole Oceanographic Institution, Woods Hole, MA 02543, USA
}

Received: 15 January 2009 - Published in eEarth Discuss.: 19 March 2009

Revised: 23 February 2010 - Accepted: 4 March 2010 - Published: 24 March 2010

\begin{abstract}
A new combined understanding of plate tectonics, Earth internal structure, and the role of impulse in deformation of the Earth's crust is presented. Plate accelerations and decelerations have been revealed by iterative filtering of the quaternion history for the Euler poles that define absolute plate motion history for the past 68 million years, and provide an unprecedented precision for plate angular rotation variations with time at 2-million year intervals. Stage poles represent the angular rotation of a plate's motion between adjacent Euler poles, and from which the maximum velocity vector for a plate can be determined. The consistent maximum velocity variations, in turn, yield consistent estimates of plate accelerations and decelerations. The fact that the $\mathrm{Pa}-$ cific plate was shown to accelerate and decelerate, implied that conservation of plate tectonic angular momentum must be globally conserved, and that is confirmed by the results shown here (total angular momentum $\sim 1.4^{+27} \mathrm{~kg} \mathrm{~m}^{2} \mathrm{~s}^{-1}$ ). Accordingly, if a plate decelerates, other plates must increase their angular momentums to compensate. In addition, the azimuth of the maximum velocity vectors yields clues as to why the "bend" in the Emperor-Hawaiian seamount trend occurred near $46 \mathrm{Myr}$. This report summarizes processing results for 12 of the 14 major tectonic plates of the Earth (except for the Juan de Fuca and Philippine plates).

Plate accelerations support the contention that plate tectonics is a product of torques that most likely are sustained by the sinking of positive density anomalies revealed by geoid anomalies of the degree 4-10 packet of the Earth's spherical harmonic coefficients. These linear positive geoid anomalies underlie plate subduction zones and are presumed due to phase changes in subducted gabbroic lithosphere at depth in the upper lower mantle (above $1200 \mathrm{~km}$ depth). The tectonic plates are pulled along by the sinking of these positive mass
\end{abstract}

Correspondence to: C. Bowin (cbowin@whoi.edu) anomalies, rather than moving at near constant velocity on the crests of convection cells driven by rising heat. The magnitude of these sinking mass anomalies is inferred also to be sufficient to overcome basal plate and transform fault frictions. These results imply that spreading centers are primarily passive reactive features, and fracture zones (and wedgeshaped sites of seafloor spreading) are adjustment zones that accommodate strains in the lithosphere. Further, the interlocked pattern of the Australian and Pacific plates the past 42 Million years (with their absolute plate motions near $90^{\circ}$ to each other) is taken as strong evidence that large thermally driven "roller" convection cells previously inferred as the driving mechanism in earlier interpretations of continental drift and plate tectonics, have not been active in the Earth's mantle the past 42 Million years, if ever.

This report also presents estimates of the changes in location and magnitude of the Earth's axis of total plate tectonic angular momentum for the past 62 million years.

\section{Introduction}

The concept of plate tectonics and seafloor spreading began 50 years ago with Harry H. Hess' 1960 preprint "Evolution Ocean Basins" which proposed that new seafloor was being created today and that ocean crust is not just an ancient relic from the past (preprint viewable at ftp://ftp.whoi. edu/pub/users/cbowin). His conclusion 14) "The continents are carried passively on the mantle with convection and do not plow through oceanic crust", and conclusion 13) "Rising limbs coming up under continental areas move the fragmenting parts away from one another at a uniform rate so a truly median ridge forms as in the Atlantic Ocean" were the heart of his new vision. Hess's Preprint (1960) was eventually published in Hess (1962).

Published by Copernicus Publications on behalf of the European Geosciences Union. 
After Hess (1960), Dietz (1961a, b) proposed the name "seafloor spreading". Vine and Matthews (1963) then explained the magnetic stripes over oceanic crust (revealed by ship and airborne magnetometers) as resulting from alternately polarized crust that recorded time variations in the polarity of the Earth's north magnetic pole. Then came the hypothesis of hot-spot plumes (Wilson, 1963, 1965) creating volcanic edifices on the ocean floor, but presumed to originate from depths in the lower mantle. Perhaps these depths are close to the core-mantle boundary (CMB), because the trends of such chains of prior extinct older, and more submerged, volcanic seamounts show no relation to the relative motions between the tectonic plates which they puncture. Morgan $(1971,1972,1973)$ used Euler poles to elucidate mathematically the spreading history of plates away from mid-ocean spreading centers, and to estimate plate absolute motions. Forsyth and Uyeda (1975) concluded that "... all the oceanic plates attached to substantial amounts of downgoing slabs move with a "terminal velocity". Thus in a little more than a decade, plate tectonics became the dominant hypothesis for understanding the tectonics of the Earth.

Many investigators concentrated on analyzing possible internal convection models that might produce the observed surface plate tectonics by using theoretical and computer simulation approaches (e.g. Ricard et al., 1993; Bercovici et al., 2000). Although the concept of plate tectonics was new, there was recognition that there exists a vast store of geologic information about past periods of mountain building and the changing patterns of Earth deformations. Thus it was broadly recognized that the present pattern of plate motions must have evolved from prior patterns. Although spreading rate changes were recognized between times of what appeared to be relatively constant plate velocities, most efforts were directed at trying to understand what prompted such episodic shifts in velocity and/or direction. Global plate tectonic analyses were usually made under the assumption of no-net-torque, which assumes constant velocities, and hence no accelerations nor decelerations. Gripp and Gordon (2002) noted that the current rotation rate of the HS3NUVEL1A plate motion model is approximately 50 percent faster than the average rotation rate since $0-47 \mathrm{Myr}$ of Watts et al. (1988) or of Petronotis and Gordon (1999). A change in plate motion rates was also noted by comparing paleomagnetic results on sedimentary rocks on the Ninetyeast Ridge, between ocean drilling sites 756 and 758, from which a decrease in the rate of northward movement of India was estimated, at about $55 \mathrm{Myr}$, from $18-19.5 \mathrm{~cm} / \mathrm{yr}$ to $4.5 \mathrm{~cm} / \mathrm{yr}$ (Klootwijk et al., 1991). Other examples include Wu et al. (2008) and Iaffaldano and Bunge (2009). Although spreading rate, and direction, changes were noted, and perhaps expected where mountain building occurred, continuous acceleration/deceleration was not considered. But now, as Plate Tectonics is at its 50th anniversary, more precise details of its very low rates of plate acceleration/deceleration are being revealed.
Initially the hotspot traces were considered to provide a means of determining absolute motions of the plates with respect to fixed source sites near the base of the mantle just above the core-mantle boundary (CMB), perhaps from the D" layer. A contrary summary, for a shallow origin for source of hotspots is summarized by Doglioni et al. (2005). There was then debate as to whether or not the Atlantic and Indian Ocean hotspot plumes are, or not, fixed in regard to each other, and to the Pacific Ocean hotspots. Then further considerations of varying mantle viscosities with depth in the mantle, suggested to some investigators, that a plume's vertical trajectory may shift laterally (by mantle advection) during its assent, with respect to its deep mantle source site, and thereby possibly explain why the bend in the Pacific Ocean's Emperor-Hawaiian seamount chain is noted in the Pacific Plate (Cande et al., 1995; Steinberger and O'Connell, 2000; Tarduno et al., 2003). Tarduno (2007) citing paleomagentic latitude variations from ODP Leg 197 samples from the Emperor ridge, suggested that track segments are dominated by mantle flow rather than plate motion for certain time intervals. Douglioni et al. (2005), offer the suggestion that the Hawaiian hotspot may originate within the asthenosphere. Molnar and Stock (1987) concluded that hotspots do not define a fixed reference system. King et al. (2002) proposed that convection-driven plate motions are intrinsically unstable due to buoyant instability, and that is responsible for episodic reorganizations of plate motion. If any of these hypotheses is the case, then hotspot tracks would not provide a link to absolute plate motions without secure knowledge of convective motions in the Earth's mantle. Torsvik et al. (2008) develop a "hybrid" model from analyses of four different reference frames (paleomagnetic, African fixed hot spot, African moving hot spot, and global moving hot spot), and conclude that "...there is still no generally accepted mechanism that consistently explains plate tectonics in the framework of mantle convection". To my knowledge, only Jin and Zhu (2004) have written that relative motions of some plates systematically slow down, whereas other plate pairs indicate accelerations, or have had almost constant relative motions.

Norton (1995, 2000, Fig. 10) superimposed transposed past locations on Asia, Africa, Antarctica, India, Australia plates, and North America, and South America, relative to the Indo-Atlantic hotspot reference frame, as if they had converged upon Hawaii. Only the North America and South America transposed traces show bends in their traces near 47 Million years, but the bend locations are not coincident, nor should they be, with the bend location in the EmperorHawaii seamount chain. He also concluded (1995) that since there was no major regional tectonic event at the $43 \mathrm{Myr}$ age of the Emperor-Hawaiian bend, that the Emperor portion was formed by a nonstationary hotspot. However, we will demonstrate, that there was a significant change in tectonic plate motions at the time of the bend (herein dated as 


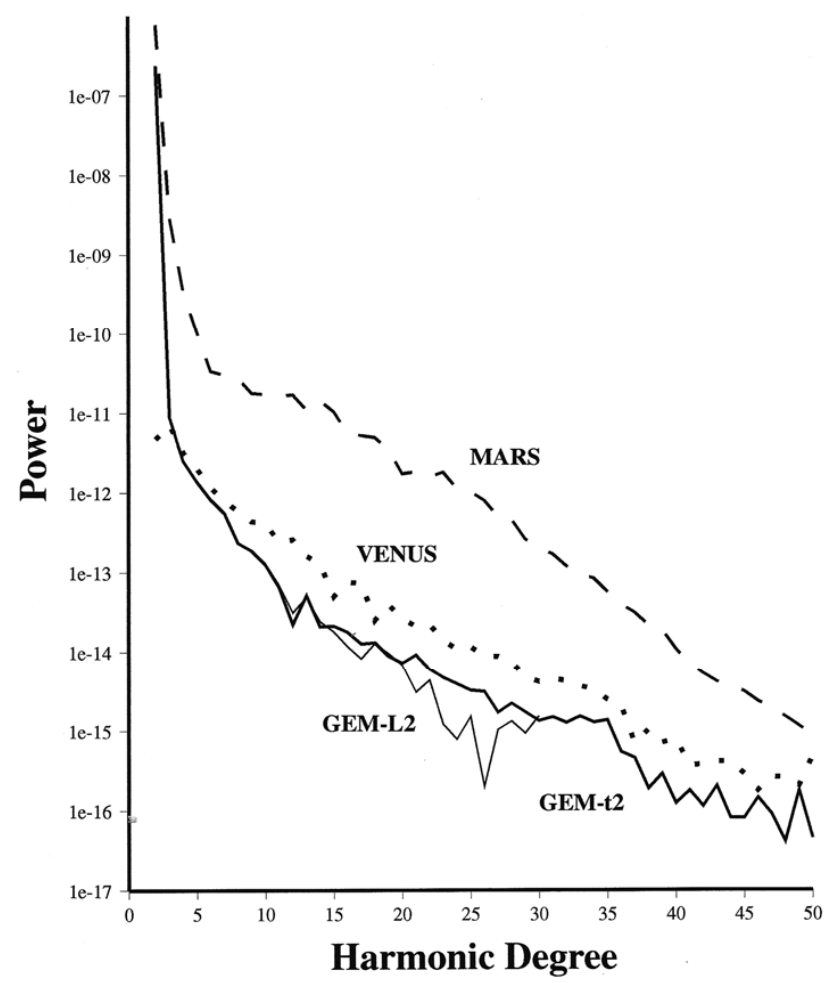

Fig. 1. Power spectra for Earth. Venus, and Mars from sets of spherical harmonic coefficients. Earth (solid line) is from GEML2 (Lerch et al., 1982) and GEM-t2 (Marsh et al., 1990), Venus (dotted line) is from Nerem et al. (1993), and Mars (dashed line) is from Smith et al. (1993). If the horizontal harmonic degree axis were plotted as a log scale, then the spectra would be nearly straight lines.

46-44 Myr when the Indian Ocean plate renewed its northward motion.

The path I traversed to be able to document that plate tectonics conserves angular momentum was an uncommon one, and also provides significant details concerning the Earth's deep structure that led to that result. My initial principal research activities at the Woods Hole Oceanographic Institution (WHOI) were involved in developing and managing a real-time marine gravity program (Bernstein and Bowin, 1963), and using gravity observations to elucidate Earth structures (Bowin, 1983, 1986, 1991, 1997; Bowin et al., 1978, 1986). Figure 1 compares spherical harmonic power spectra for the planetary bodies Earth, Venus, and Mars. In an early geophysical manuscript of mine, I noted that in the Earth's power spectrum, harmonic degrees 2 and 3 have a much steeper slope than those of the higher harmonic degrees, and (as a geologist) suggested that degrees 2 and 3 appeared to primarily have a different source than the higher degree contributions. Reviewers ridiculed that suggestion, stating that all masses contribute to all degrees (which they do), and that one cannot examine separate packets of harmonic degrees, and publication of that manuscript was denied. I

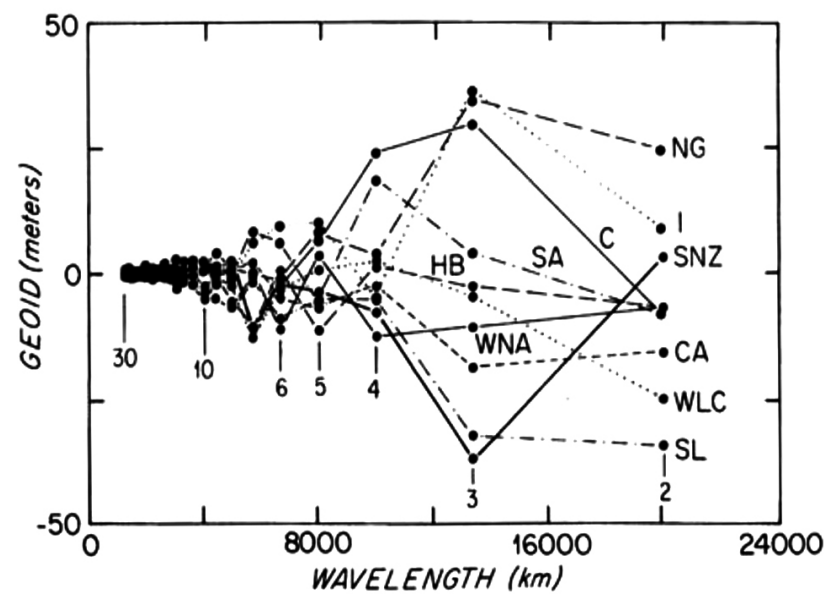

Fig. 2. Magnitudes of individual harmonic degree contributions for the Earth's 10 major geoid anomalies. Values are computed from GEM-9 coefficients, referenced with reciprocal flattening of 298.257 (actual Earth flattening). Four positive anomalies are New Guinea (NG), Iceland (I), Crozet (C), and South America (SA). Six negative anomalies are Indian Ocean (Sri Lanka) (SL), west of lower California (WLC), central Asia (CA), south of New Zealand (SNZ), west North Atlantic (WNA), and Hudson Bay (HB). See Fig. 5, Degree 2-30 map for locations.

now can look at Fig. 1, and immediately be sure that both the Earth and Mars have dense deep cores, whereas Venus does not.

Years later (as a geophysicist), in order for me to try to better comprehend the variations in the power spectra for the planets Earth, Venus, and Mars, as well as variations in the harmonic degree contributions of the Earth's major geoid anomalies (Fig. 2), I thought of constructing point mass Earth models. Using balanced 2 positive and 2 negative point masses at various depths (4000, 2900, 2000, 1000, 500, and $100 \mathrm{~km}$ ), I calculated each depth model's spherical harmonic coefficients. I could then examine how their surface patterns varied as a function of the depths to the balanced point masses. For these 2 balance point mass models, the odd order harmonic degree coefficients are zero Therefore, a similar set of spherical coefficients were calculated for balanced 3 positive and 3 negative point mass anomalies for the same set of depths. Figure 3 shows a set of geoid cumulative percent curves of their degree 30 value, at a location directly above a positive model point mass, for the 3 balanced positive and negative point mass models. By using a percent of the cumulative degree 30 value, the curves become independent of the actual point mass values. In that figure one can see that by fitting spline functions across the depth models at each odd degree, depths $(d)$ of an equivalent point mass can be estimated from the geoid percent of its cumulative degree 30 value. Similar spline functions were also determined for gravity (the vertical derivative of the geoid, $\left(1 / d^{2}\right)$, the vertical gravity gradient $\left(1 / d^{3}\right)$, and the vertical gradient of the 


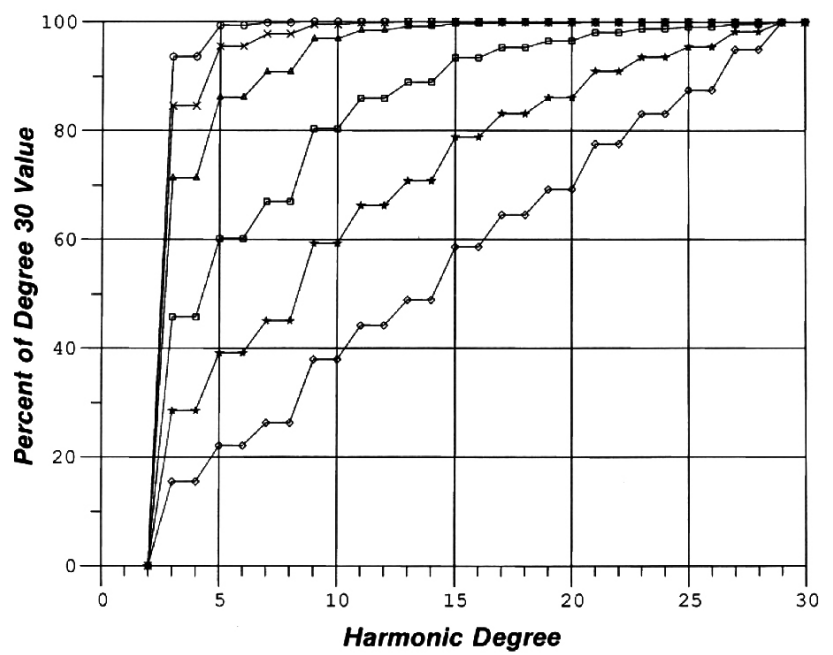

Fig. 3. Set of geoid cumulative percent curves at a location directly above a positive model point mass. Curves are computed from spherical harmonic coefficients determined from balanced sets of point masses (three positive and three negative) at the label depths. Curves show summed contributions from degrees 2-30 for depths (top to bottom) 4000, 2900, 2000, 1000, 500, and $100 \mathrm{~km}$.

vertical gravity gradient $\left(1 / d^{4}\right)$. These spline curves proved very useful, because by calculating actual spherical harmonic results at the center locations of Earth geoid anomaly features, an equivalent point mass depth at each harmonic degree, and for each vertical derivative of the gravity potential field, could be estimated. Of course, then having a depth for a point mass, the mass itself could be calculated from the simple point mass equation for either, or both, the geoid [GM/d] or gravity $\left[\mathrm{GM} / d^{2}\right]$.

Figure 4 gives examples for both the South American geoid high (SA), and the New Guinea geoid (NG) high. Note that for the South American geoid high, all its equivalent point mass depths lie close to $1200 \mathrm{~km}$, and that all the vertical derivatives have the same point mass depths. The South American geoid high is the only plate convergent high seen in the Earth's spherical harmonic degree 410 packet (which shows a band of positive geoid anomalies at all plate convergent sites) that is also observable in the geoid degree 2-10 and 2-30 maps (see Fig. 5 from Bowin, 1991). This fact indicates that the positive mass anomalies that cause the degree 4-10 geoid anomaly bands lie near a single source depth, shallower than the $1200 \mathrm{~km}$ point-mass depth. Hence, this is evidence that there are not significant negative mass anomalies produced by a downward deflection neither of the seafloor nor at the core/mantle boundary as a result of subduction motions of the lithosphere at this plate convergent site. Note further, that the large negative gravity anomalies associated with deep-sea trenches, do not appear in the gravity harmonic degree spectrum until about greater than degree 40 (see Fig. 7) because of their short
(SA)
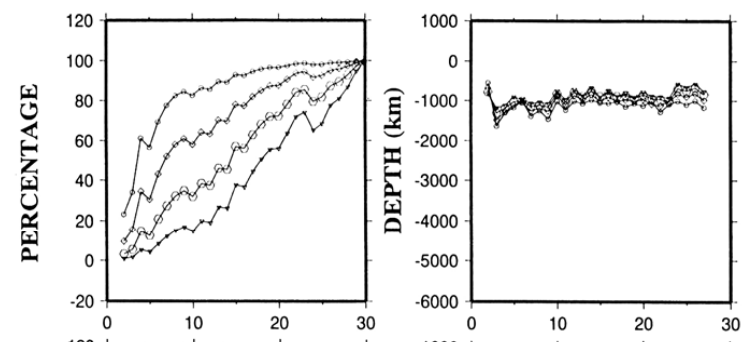

(NG)
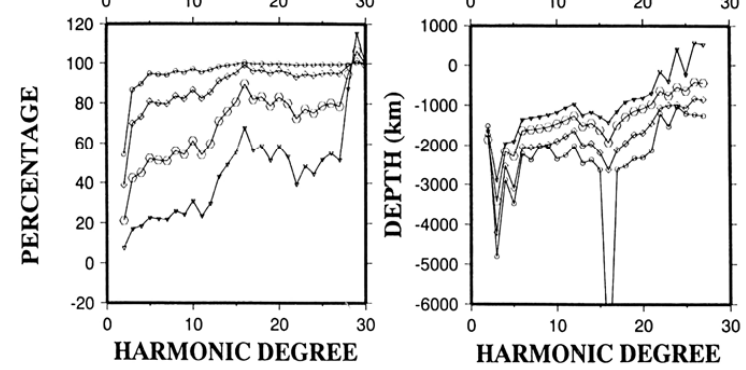

Fig. 4. Percentage cumulative contribution curves (CCC), estimated equivalent point-mass depth curves, and estimated anomalous mass. Depths are estimated from the percentage CCC using spline function coefficients for each harmonic degree. Spline functions are from model sets of 2 and 3 balanced point masses at depths of 100, 500, 1000, 2900, and $4000 \mathrm{~km}$. SA indicates South America GEM99t2 degree 2-10 geoid high, and NG indicates New Guinea GEMt2 degree 2-10 geoid high.

equivalent wavelength. So the negative trench mass anomalies cannot contribute significantly to the configuration of the degree 4-10 gravity nor geoid fields. However, such negative seafloor and core/mantle deflections, were an integral part of the dynamic tomography hypotheses (e.g. Hager, 1981; Hager, 1984; Richards and Hager, 1984; Hager et al., 1985; Ricard et al., 1993). Bercovici et al. (2000) also concluded that attempts to detect dynamic topography have been unsuccessful.

A comparison of the geoid anomaly along an east-west profile across the South American Andes near $20^{\circ} \mathrm{S}$ with topography is shown in Fig. 6, and clearly shows a $25 \mathrm{~m}$ high rise in the geoid associated with the mass of the high Andean topography being superimposed on a much broader $30 \mathrm{~m}$ geoid high associated with the deep positive mass anomaly of the degree 4-10 spherical harmonic packet at this subduction zone seen in Fig. 5. Again, note the very small negative geoid deflection associated with the Peru Trench (Fig. 6), and how its integral is very tiny compared with the geoid anomaly signal from the geoid contribution arising from the degree 410 geoid field. Thus, a significant negative mass anomaly contribution from depression of the seafloor at plate subduction sites, as per the dynamic tomography hypothesis is not substantiated.

Figure 8 from Bowin (2000) summarizes the magnitudes of the mass anomalies that produce the Earth's gravity and geoid anomalies. The greatest mass anomalies, I infer, 
GEOID

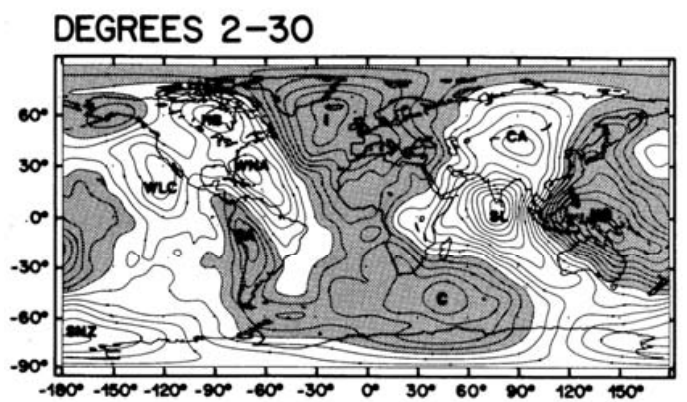

DEGREES $2-10$

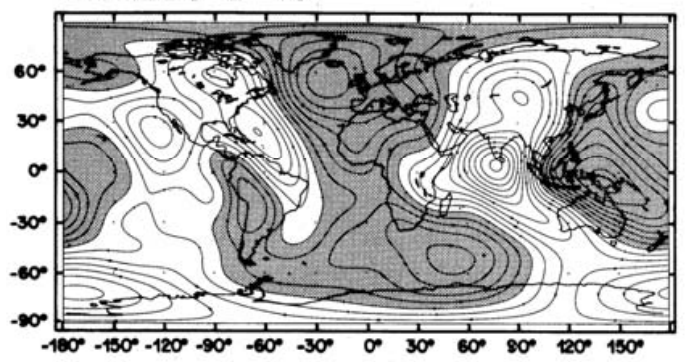

DEGREES $4-10$

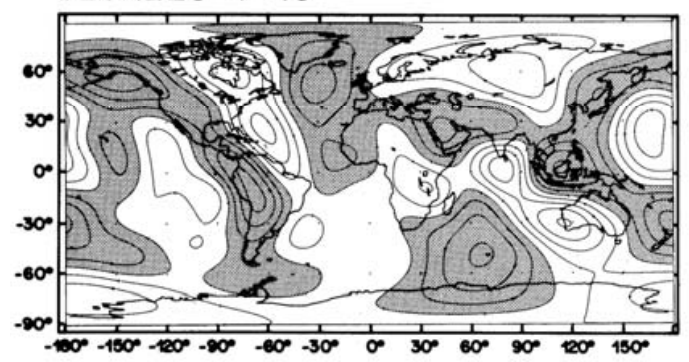

DEGREES 2-3

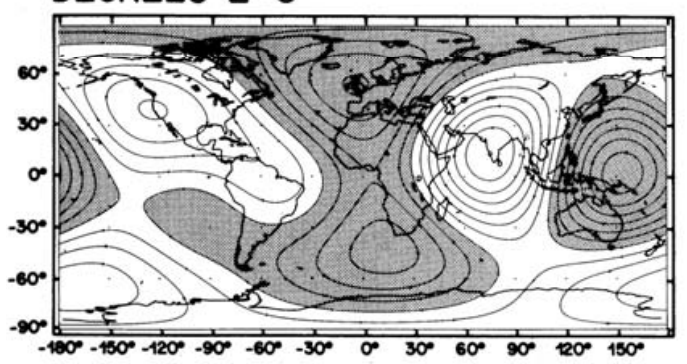

GRAVITY

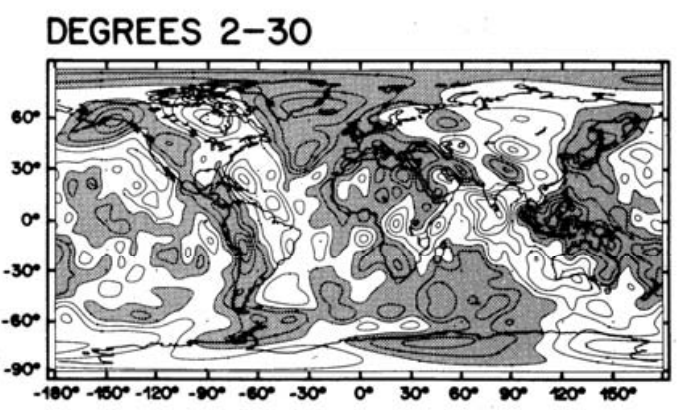

DEGREES 2-10

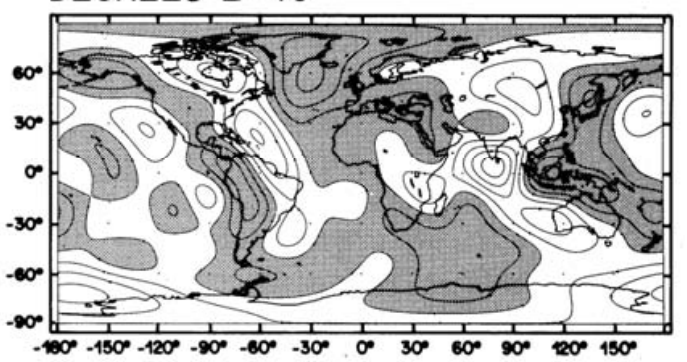

DEGREES 4-10

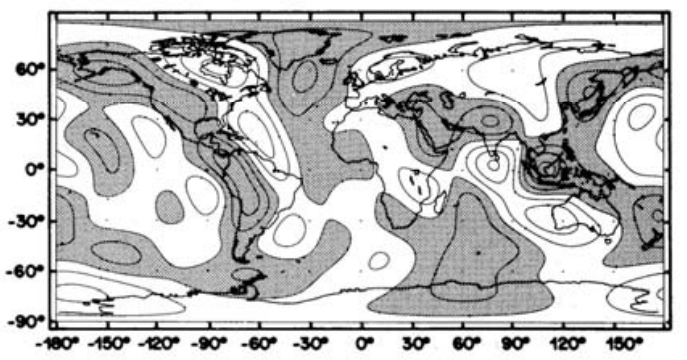

DEGREES 2-3

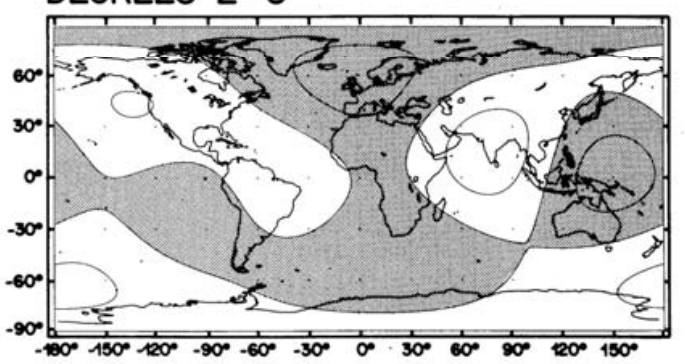

Fig. 5. Geoid and gravity anomaly maps from GEM-L2 spherical harmonic coefficients. Referenced to ellipsoid with reciprocal flattening of 298.257 (actual Earth Flattening). Contour intervals are $10 \mathrm{~m}$ and $20 \mathrm{mGal}$, respectively. Degree 2-30 maps obtained by summing contributions from degrees 2 through 30. Degree 2-10, degree 4-10, and degree 2-3 maps similarly obtained. In the geoid degree 2-30 map, the 10 major geoid anomalies are labeled, see Fig. 2 caption for their identity.

arise from $2-3 \mathrm{~km}$ of relief in topography at the core-mantle boundary. The second greatest mass anomalies arise from phase changes of olivine and pyroxenes to denser phases at depth (shallower than $1200 \mathrm{~km}$ ) in subducted oceanic crust and lithosphere that are revealed in the 4-10 degree spherical harmonic geoid field pattern.
After publishing Bowin (2000), I then turned my attention to attempting to find a link between the band of positive mass anomalies beneath present plate convergent sites, revealed in the geoid harmonic degree 4-10 packet, and how the Earth's major plates move. I was intrigued by the clever geometric solution of Harada and Hamano (2000) for 


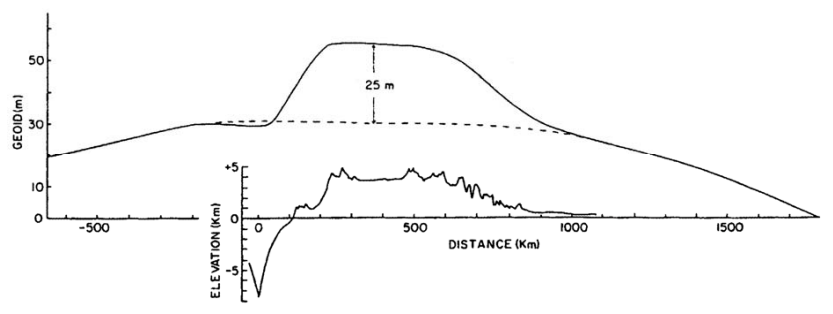

Fig. 6. Geoid height and topography along an east-west profile around $20^{\circ} \mathrm{S}$. The horizontal distance is measured relative to the Oceanic trench axis. A distinct positive rise in the geoid curve, $N=25 \mathrm{~m}$ correlates with the high topography of the Altipano-Puna and the Eastern Cordillera. The dashed line is drawn in continuation of the broader regional maximum. Reprinted from Foidevaux and Isacks (1984) with permission.

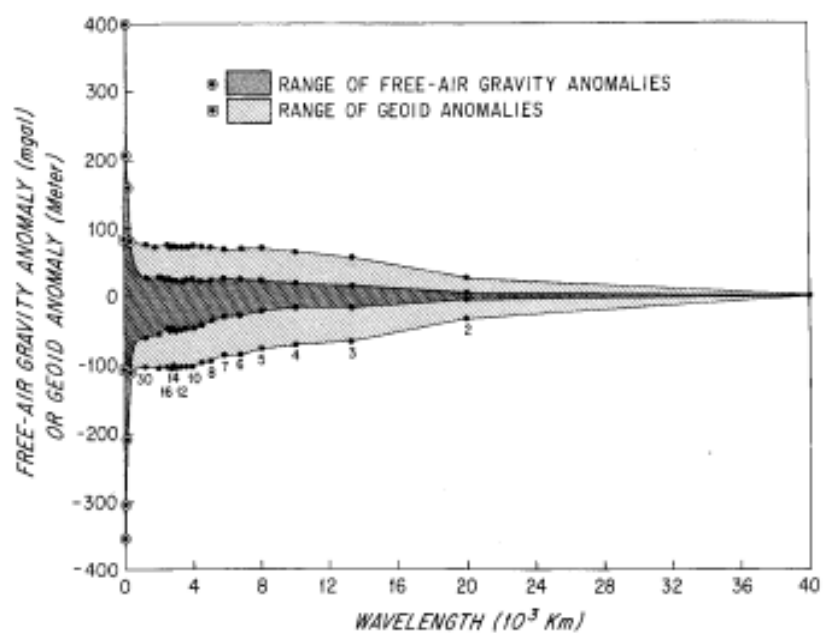

Fig. 7. Comparison of the ranges of free-air gravity anomalies and geoid anomalies as a function of anomaly wavelength. The numbered dots are computed from spherical harmonic coefficients (GEM-9) (Learch et al., 1979). The circled dots at zero wavelength ( -380 and $+400 \mathrm{mGal}$ ) show the range of point gravity measurements from a representative sample of global observations. The three other circled dots, not quite at zero wavelength, indicate the range of $20^{\prime} \times 20^{\prime}, 10 \times 10$, and $20 \times 20$ averaged gravity measurements in the Caribbean region (Bowin, 1976). The squared dot geoid values at zero wavelength are derived from map by Rapp (1979). Note that the great increase in the range of gravity anomalies only occurs at very short wavelengths. Reprinted from Bowin (1983) with permission.

determining Euler poles for the Pacific Plate at $2 \mathrm{Myr}$ intervals. Their paper appears largely to have been ignored by the tectonic/geophysical community, but I liked the high resolution of the $2 \mathrm{Myr}$ spaced Pacific Plate Euler pole estimates, even though, for me, their resulting locations for the maximum Pacific Plate velocity vectors, yielded slightly erratic locations of the $2 \mathrm{Myr}$ positions of the Pacific Plate maximum velocity values. However, my analyses showed

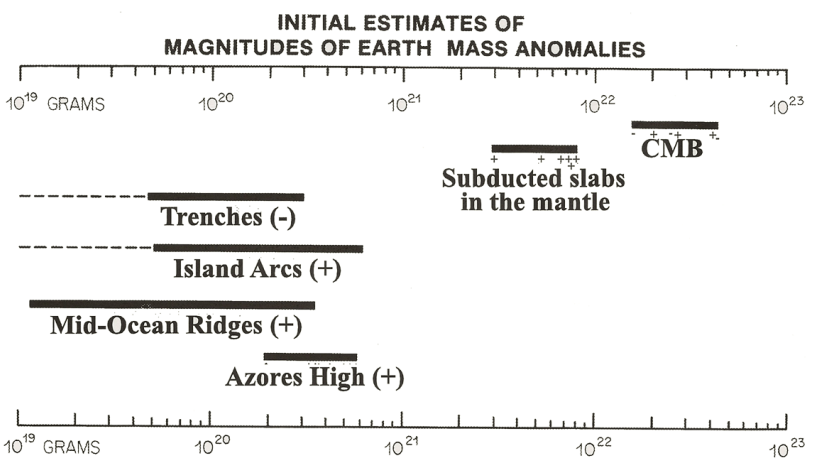

Fig. 8. Initial estimates of the magnitudes of Earth mass anomalies. Estimates are calculated from ratio of gravity anomaly divided by geoid anomaly values at anomaly centers.

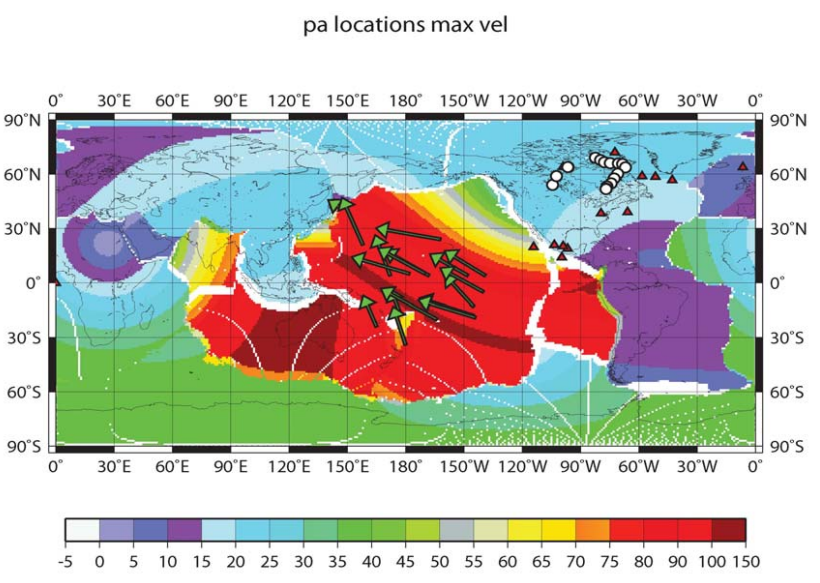

Fig. 9. Pacific Plate maximum velocity vectors (green arrows) computed from stage poles (Harada and Hamano, 2000). Vector length is proportional to plate velocity. White circles are Euler poles, red triangles are stage pole locations.

(Fig. 9), those maximum velocity vectors pointed northward for ages along the Emperor seamount trend, and eastward along the Hawaiian seamount trend. Also the maximum velocity values showed a definite pattern, although with noise, of increasing velocity with time, along both the Emperor and Hawaiian trends. In seeking a method to smooth filter a series of Euler poles, I came in contact with Harry Kuiper in The Netherlands. He developed an iterative filtering subroutine for his quaternion processing CWMTX package. We presented a poster at the 2005 AGU Fall meeting (viewable at ftp://ftp.whoi.edu/pub/users/cbowin/ which demonstrated the success of his iterative smoothing program. This iterative smoothing capability, then provided a Pacific Plate set of smoothed Euler poles to be used in estimating $2 \mathrm{Myr}$ spaced Euler poles for 12 of the 14 major plates utilizing Jason Morgan's scalar Fortran code, Those results then demonstrated that plates accelerate and decelerate, and that, in turn, suggested that plate tectonics conserves angular momentum 
(see Fig. 14), and therefore that impulse forces produce the Earth's surface deformations (Bowin, 2009).

Bowin (2000) provided a decomposition of the planet Earth's potential field into three main component packets of spherical harmonic degrees and orders (see Fig. 8). The greatest contribution to the Earth's geoid comprises degrees and orders 2-3 (which have equivalent point mass depths deeper than the CMB at $2900 \mathrm{~km}$, and have the Earth's greatest mass anomalies $2-4 \times 10^{22} \mathrm{~g}$ ). The second greatest geoid contribution arises from degrees 4-10, which reveal bands of positive geoid anomalies beneath the sites of plate subduction that have the Earth's second greatest mass anomalies $\left(3-7 \times 10^{21} \mathrm{~g}\right)$; and thirdly, the geoid packet of degrees 11- infinity, which have the smallest mass anomalies $\left(10^{19}\right.$ $7 \times 10^{20} \mathrm{~g}$ ), but being closer to the Earth's surface, this third packet dominates the contributions to the Earth's surface gravity anomalies, which vary as one over depth squared. These interpretations were convincing to me, but contrary to the prevailing hypothesis of dynamic viscous mantle flow, which explained the lack of correspondence between the Earth's geoid anomalies (degrees 2-30) and surface plate tectonics because of an inferred triplet of mass anomalies associated with subducting plates (Hager and O'Connell, 1981; Hager, 1984; Ricard et al., 1993).

The triplet comprises two negative mass anomalies, one at the seafloor where the lithosphere is assumed to be depressed downward - displacing ocean crust by water - from the downward motion of the subducted sinking slab; and the other is assumed to be at the core-mantle boundary (CMB), where the nickel-iron of the core would be depressed toward the center of the Earth by the subducting silicate slab pressing downward on the CMB. The positive mass anomaly, that drives the two negative viscous flow interface deformations, is the positive mass anomaly within the subducted slab due to mineral phase changes in the gabbroic crust when taken to depth in the peridotitic mantle.

The dynamic viscous mantle flow hypothesis was very compelling until the gravity to geoid anomaly ratio of the South American subduction zone was analyzed (Bowin, 2000, Fig. 13 (SA)), and all its geoid anomaly derivatives have a common equivalent single positive point mass source at about $1200 \mathrm{~km}$ depth was indicated for all harmonic degrees 2 to 30 . This is contrary to the triplet mass anomaly distribution expected from the dynamic viscous mantle flow models. Note, also, that the South American Andes geoid high is the only subduction geoid high of the 4-10 degree geoid field that is evident in the global geoid field. A shorter wavelength geoid high $(\sim 25 \mathrm{~m})$ coincident with the Andes mountains is superimposed upon the broader regional South American degree 4-10 geoid high of about $30 \mathrm{~m}$ (Fig. 6).

Although viscous mantle flow should produce surface and deep boundary deflections, for the Earth, I infer such deflections must be minimal. Slab densities identified in forward modeling (Bowin, 2000) are about 200 times smaller than those used in the dynamic topography modeling, yet yield driving force estimates that agree with prior force estimates based on thermal modeling, further suggesting that the dynamic topography solutions had to overestimate subduction densities in order to effect sufficient deflections on the surface and CMB to produce their great degree 2 -3 contributions of the Earth's geoid field. Hence, I turned to examining plate tectonic motions in an attempt to find a relationship with the distribution of positive lower mantle density anomalies that appear in the spherical harmonic geoid degree 4-10 packet cited above. And, that relation is now herein revealed.

\section{Improved resolution of absolute Pacific plate motions}

Harada and Hamano (2000) provided a new way for geometrically estimating past Euler pole positions for the Pacific plate; evenly distribute in time (at 2 or $4 \mathrm{Myr}$ ) intervals. Their method assumed a fixed hot-spot reference frame, and depended upon the existence of three hotspot tracks (EmperorHawaiian, Easter-Line, and Louisville) delineated on satellite gravity maps (Sandwell and Smith, 1997) on the same Pacific plate. Using the spherical triangle defined by the present day locations for those three hot-spots as a fixed template for identifying, which past points, along each plume trace congruently link together. Then by using the conjugate points along the Emperor-Hawaiian and Louisville seamount chains, they could, one at a time, bisect the arc between such point and its zero age location. Each arc separation distance represents an accumulation rotation angle from the present day location back to a prior time. Using the two great circle arcs, normal's to each of the two arcs at their bisect locations, their point of intersection was then calculated. The sites of intersection of the Emperor-Hawaiian with the Louisville bisect great circle arcs, then provide an estimate of the location for the accumulative plate rotation axis (an Euler pole) for each conjugate point along the plume traces. For the more recent ages, the arc lines to be bisected become shorter and shorter, leading to less precise estimates of the accumulation rotation pole axes.

Harada and Hamano (2000) then used those calculated Pacific Plate rotation poles to estimate plume tracks for Bowie, Cobb, Carolina, Guadalupe, Socorro, Marquesas, Pitcairn, Macdonald, Phoenix, Foundation, Gilbert-Marshall, Tahiti, and Samoa seamount chains with rather compelling success (their Plate 1) without using age data. Such results support the assumption of a fixed hot-spot reference frame for the entire Pacific plate. To assign ages to the geometrically established plume-trace points, they then plotted the accumulation angle verses radiometrically established ages from rocks along the plume traces to calibrate the ages of the total rotation points along each plumes trace (their Fig. 4). For this study, a digital file of the $2 \mathrm{Myr}$ accumulation pole data of their Table 3 was prepared (see Supplementary Material S1, http://www.electronic-earth.net/5/1/2010/ ee-5-1-2010-supplement.zip). Latitude and longitude had to 
be time shifted to be associated with the end of each time interval (rather than the beginning as published, so as to be compatible with Jason Morgan's Fortran code "mpfin.f" received from Gary Acton, which was modified to accommodate the author's data file needs, and renamed mpfinf3.f.

A Quicktime movie of Harada and Hamano (2000) Pacific plate absolute motions from $68 \mathrm{Myr}$ at $4 \mathrm{Myr}$ intervals (Bowin, 2004; Bowin and Kuiper, 2005) can be viewed at www.whoi.edu/scc, No. 12. A new movie version with $2 \mathrm{Myr}$ interval is included in the Supplement (http://www.electronic-earth.net/5/1/2010/ ee-5-1-2010-supplement.zip). The changing velocity colors in that movie was the first clear demonstration of $\mathrm{Pa}$ cific Plate acceleration. The somewhat erratic location movements of the Pacific plate at $4 \mathrm{Myr}$ intervals in that movie, as well as the small irregularities in the positions and spacing's of the Pacific plate Euler Poles, although much smoother and consistent than previously published results, suggested that, most likely, the Pacific plate history would, in reality, have had a much smoother and coherent motion history.

\section{Filtering of euler poles}

The Pacific Plate was originally documented (Bowin, 2004) to have had two periods of acceleration during the past 68 million years. That conclusion was obvious from a plot of maximum velocities for the Pacific plate attained using the $4 \mathrm{Myr}$ spaced stage poles of Harada and Hamano (2000), and is also clear in the color velocity changes shown by the Pacific Plate in the QuickTime movie viewable at www.whoi.edu/scc, No. 12. Furthermore, the maximum velocity vectors for the 66 to $48 \mathrm{Myr}$ period point toward Sakalin (the westernmost edge of the North American Plate) for the stage poles from the Emperor seamount chain, but towards the Philippine arc for the stage poles along the Hawaiian trend (see figure in Bowin and Kuiper (2005) poster, viewable at ftp://ftp.whoi.edu/pub/users/cbowin and named "poster_agu_2005.pdf". My interpretation then, and now, is that phase changes, such as pyroxene to spinel provides the deep positive mass anomalies observed in the degree 4-10 packet of geoid anomalies, and that the sinking of these positive mass anomalies provides the driving force for plate tectonics (Bowin, 2000). The change in direction of the Pacific plate maximum velocity vector between $48 \mathrm{Myr}$ and $44 \mathrm{Myr}$ resulted in a shift from underthrusting the westernmost edge of the North American plate to underthrusting the Philippine and Eurasian plates at about $44 \mathrm{Myr}$. Such a shift is inferred to have resulted from a change in the integral of the torques from the sinking phase-change positive mass anomalies at depth beneath the Aleutian, Kuril, Japan, Izu-Bonin, Ryuku, Marianna, Yap, and Philippine trenches, . Many papers; e.g. Forseyth and Uyeda (1973), Chapple and Tullis (1977), Hager and O'Connell (1981), Ricard et al. (1993), Conrad and Lithgow-Bertelloni (2002), and Iaffaldano and
Bunge (2009) have also concluded that subductiion is the primary driver for plate tectonics, but not directly linking it to the positive mass anomalies of the spherical harmonic degree 4-10 geoid.

The Pacific Plate is most unlikely to have moved along the somewhat erratic stage pole pattern of Harada and Hamano (2000), hence, some method for filtering (smoothing) a series of Euler pole quaternions was sought to obtain a more realistic progression for the motions that the Pacific plate may have actually followed.

How to filter (smooth) a series of Euler poles became the next objective, which the author likens to that of applying a spline function with adjustable tension across a series of Euler poles. A web search did not provide an answer, but did indicate the existence of the "CwMtx library for matrix, vector and quaternion math" written in C++ by Harry Kuiper. Following an exchange of emails, Kuiper prepared a quaternion filter routine that has been herein used for iterative smooth filtering of the Pacific, and other plate's Euler poles, for this study.

The quaternion filtering routine provides for selecting the number of iterations to be used, and for subdividing a sequence of quaternions (from Euler or stage poles) into separate segments if desired. I do not know of any way to estimate an optimum number of iterations. My first use was to try 1000 iterations in filtering the original published Harada and Hamano (2000) $68 \mathrm{Myr}$ to $0 \mathrm{Myr}$ set of Pacific plate Euler poles (identified by "NOIT", for no iterations), as two segments divided at $46 \mathrm{Myr}$ (68-48 Myr and 44-0 Myr), identified by "4448". The use of an iteration number of 1, makes very little change to the original Euler pole locations, whereas a very large number of iterations was expected to reduce the original to essentially a single Euler pole near the original's mid-point. These first results (Bowin and Kuiper, 2005) were presented at a Poster Session during the 2005 Spring AGU Meeting in Montreal used 1000 iterations (Poster viewable at $\mathrm{ftp} / / / \mathrm{ftp}$.whoi.edu/pub/users/cbowin as "poster_agu_2005.pdf"). The most striking result was the sharp bend in the stage pole locations of the 1000 iteration results for the Nazca plate at $46 \mathrm{Myr}$, which mimicked the Pacific plate's bend in the trace of the Emperor-Hawaiian seamounts. Pulling That striking result out of the noise of the NOIT Nazca stage pole pattern gave confidence in the filtering procedure. Since 1000 iterations was just a guess, a series of iterations at different powers' of 2 were made for the Nazca plate to get a sense of how the number of iterations affect the filtering of the Euler and stage poles (see Fig. 10 for a sampling of such plots). From those plots, 1024 iterations was selected for further processing because it gave the smoothest stage pole sequence (without anomalous perturbations), and yet retained a sharp change in trend at $46 \mathrm{Myr}$. Whether other nearby iteration numbers might prove superior, I leave to future study.

For this present paper, an iteration number of $2^{10}$ $(=1024)$ is used (note, the 1024 filtered results for the 

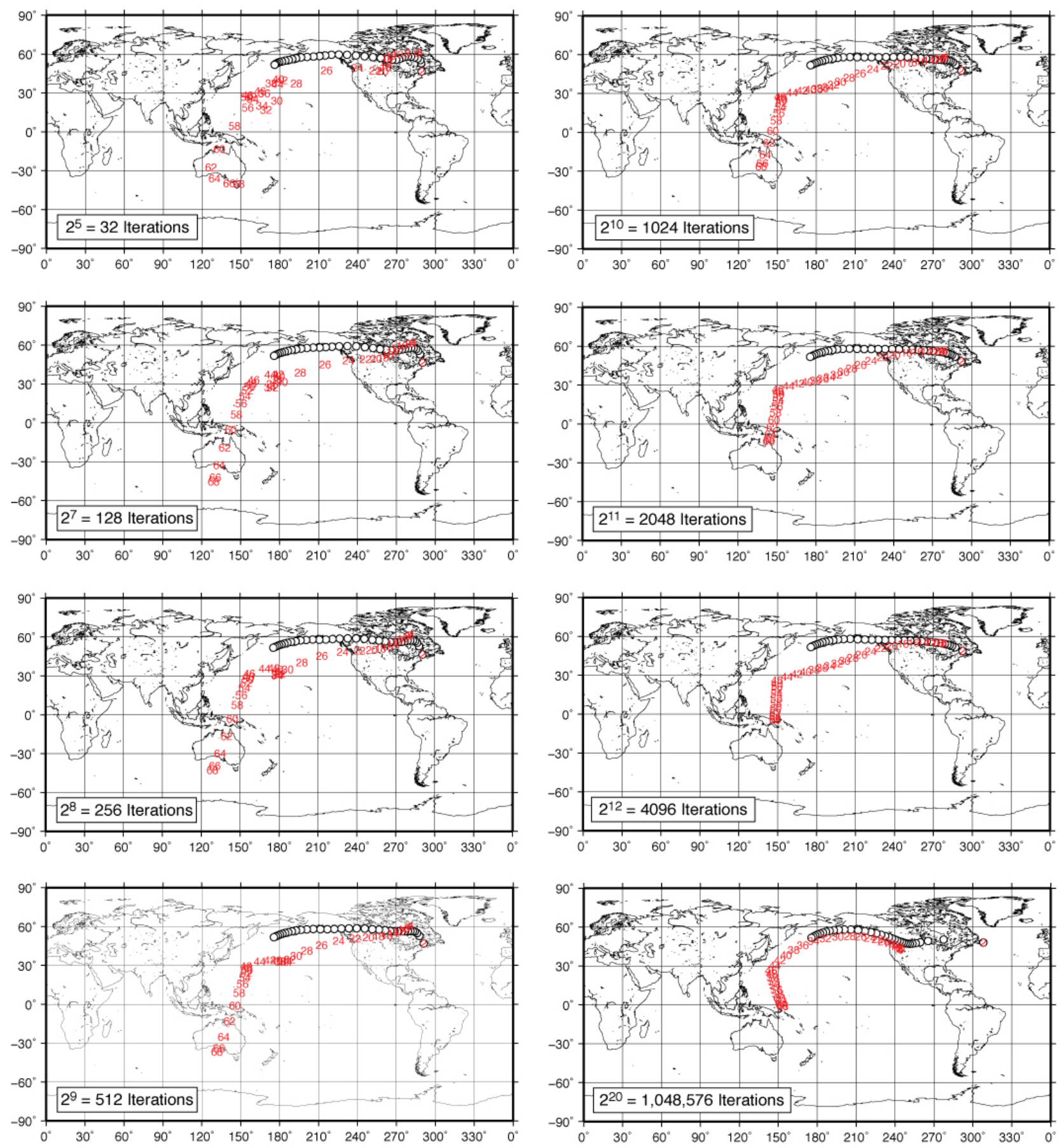

Fig. 10. Examples of quaternion smoothing from utilizing differing numbers of iterations.

12 plates processed are provided in the Supplementary Material (S4, http://www.electronic-earth.net/5/1/2010/ ee-5-1-2010-supplement.zip)). As noted previously, the youngest Pacific Euler pole locations had very short arc distances to be bisected, and thus those poles had the largest uncertainties. For this study the 6, 4, 2 Myr Pacific Euler pole data were replaced with interpolated values between the filtered $8 \mathrm{Myr}$ smoothed Euler pole and the $0 \mathrm{Myr}$ absolute Euler pole data from Gordon and Jurdy (1986) and Gripp and Gordon (1990).

Various tests using the Euler pole histories of Gordon and Jurdy (1986), Gripp and Gordon (1990), Engebretson, Cox, and Gordon (1985), and Jin and Zhu (2003) were initially conducted, but afterwards, I concentrated on using 
Table 1. Summary of plate data used in this report. The columns from the left are: Plate number, Plate ID label letters, Plate name, Age range for Euler poles, Reference for source data. HS frame refers to a global "hotspot" absolute reference frame. Details of Euler poles and age range date given in the Supplementary Material (S1, http://www.electronic-earth.net/5/1/2010/ee-5-1-2010-supplement.zip).

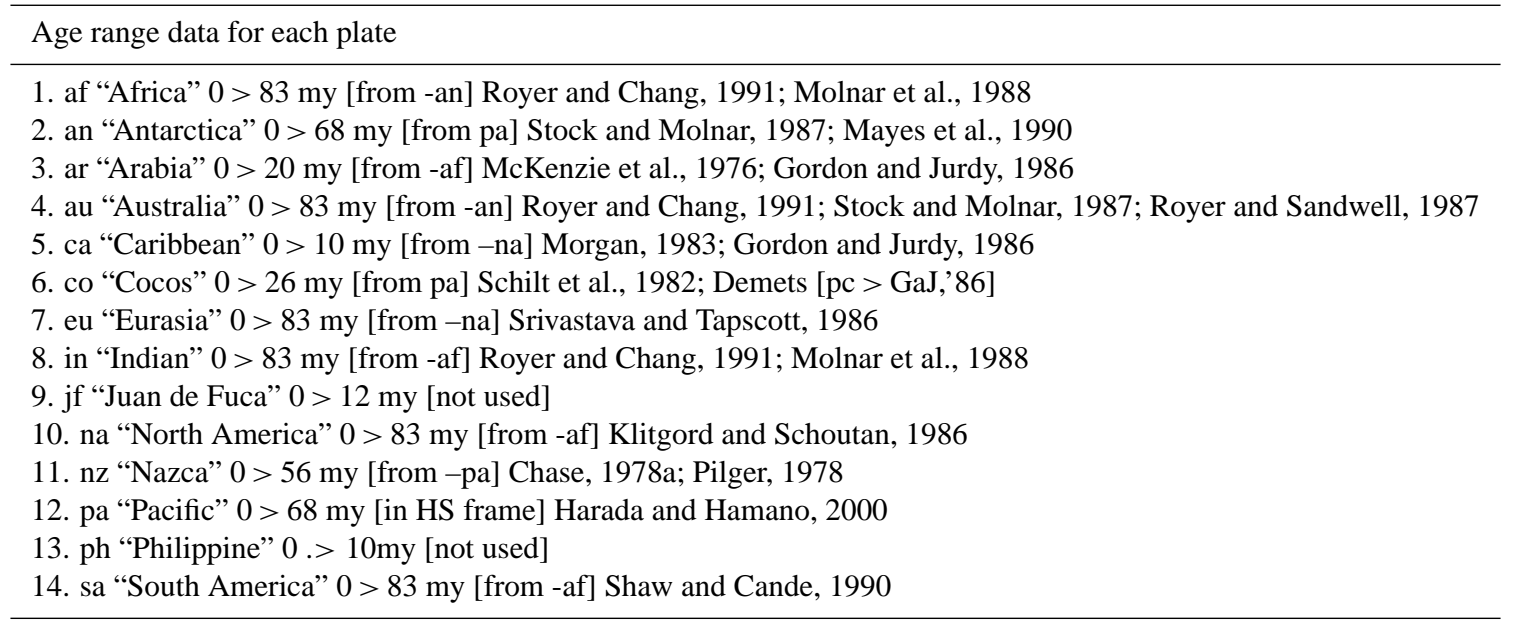

the Harada and Hamano (2000) data which provided absolute Pacific Plate Euler pole estimates at $2 \mathrm{Myr}$ intervals. These estimates provided a primary hotspot reference for converting relative poles between two plates into estimates of each plate's absolute Euler poles, also at $2 \mathrm{Myr}$ intervals, via code modified from Morgan's original Fortran program. The plate-pair data utilized here is summarized in Table 1, and in the Supplementary Material (S1, http://www. electronic-earth.net/5/1/2010/ee-5-1-2010-supplement.zip).

Morgan's code treats angular momentum as a scalar, which then allows positive or negative rotations depending upon the order in which the two input Euler poles are processed. That is why the Pacific plate Euler poles before filtering plot in the Northern Hemisphere (Fig. 11), whereas later, with quaternion filtering, using the normal convention of right-hand-rule (treating angular momentum as a pseudovector) the Euler rotations are always positive, the filtered Pacific plate Euler poles plot in the Southern Hemisphere (Fig. 12 for 4448 data,).

The most striking filter result shown in the 2005 AGU poster was the mirroring of the bend in the EmperorHawaiian seamount chain in the locations of the 4448 filtered stage pole locations for the absolute motions of the Nazca plate (plate No. 11, Fig. 12). Pulling this striking result out the noise of the quasi random stage pole locations before filtering (Fig. 11), indeed, gave credence to this quaternion filtering methodology. Interestingly, and probably profound, for understanding the tectonics of Plate Tectonics, is that, of the 14 plates analyzed, the Nazca plate is the only one that has a pattern revealing such a pronounced bend in stage pole trend at 46 Myr. Additionally, the Nazca plate is the largest of only three plates (Cocos, and Juan de Fuca are the other two) that are separated by a spreading center from another plate that is being pulled by an opposing subduction zone.
It is interesting to note that in Norton (2000, Fig. 10) that both North America and South America motions relative to the Pacific show sharp changes in linear trend near $47 \mathrm{Myr}$ when translocated to start at Hawaii. Such correspondence in timing of changes in plate motion trajectories near $47 \mathrm{Myr}$ is here interpreted as North and South American (and Australian) plate motion responses corresponding to the conservation of total plate tectonic angular momentum. The North America-Pacific boundary is a subduction/transcurrent fault (San Andreas) zone; and the South America-Nazca boundary is one of subduction of the Nazca Plate. In the same figure, the Australian Plate also shows a sharp change of trend at $47 \mathrm{Myr}$, but only of about 40 degrees, rather than the near 60 degree change of the North and South America plates, and the Emperor-Hawaiian seamount bend.

Maximum plate velocity data for the NOIT and the 4448 quaternion filtering verses time are displayed in Fig. 13, for PA Plate (12), NZ Plate (11), AU Plate (4), and AF Plate (1), along with the velocity vector's azimuth, and acceleration (in $\mathrm{mm} / \mathrm{yr} / \mathrm{Myr}$ ). Plots for all filtered plates are given in the Supplementary Material (S2, http://www.electronic-earth.net/5/ 1/2010/ee-5-1-2010-supplement.zip). These plots demonstrate smoothly varying plate velocities, and, in turn, provide the first comprehensive estimates of the plates' low acceleration/deceleration values (mm/yr/Myr). Figure 13 shows both similarities and differences between the original results before interative filtering (NOIT) and the initial 4448 twosegment 4448 quaternion filtering results.

The estimated acceleration values found in this study are about $10^{-8}$ times smaller in magnitude than typical plate velocities. No wonder, then, that plate acceleration's have been so difficult to discern. Prior Euler and stage poles have been too coarse to resolve such low acceleration/deceleration rates. This is also why prior no-net-torque solutions have 
NOIT
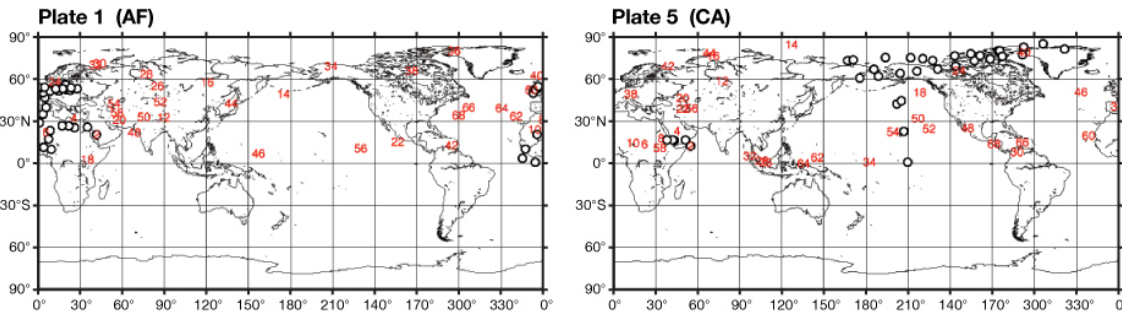

Plate 2 (AN)

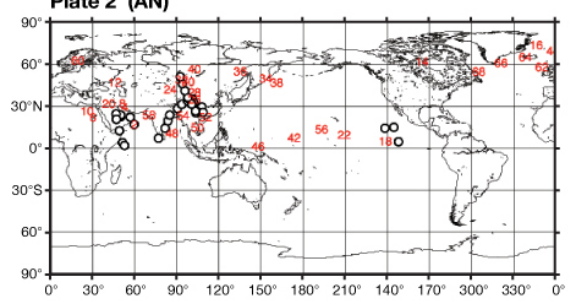

Plate 3 (AR)
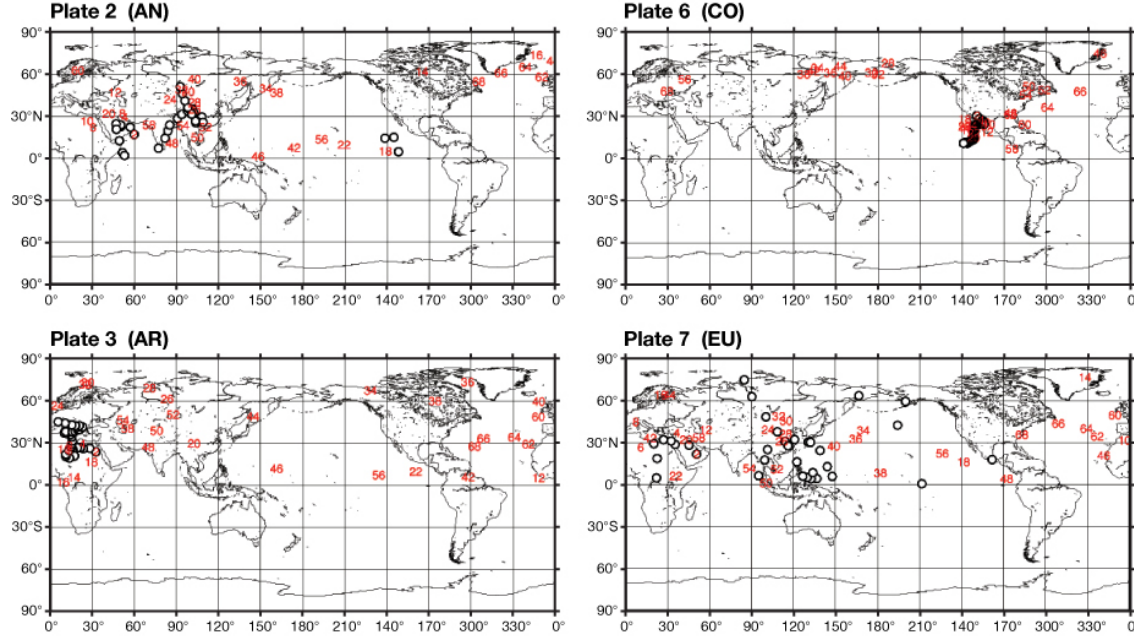

Plate 7 (EU)

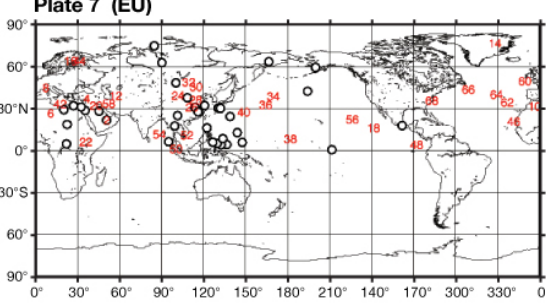

Plate 4 (AU)

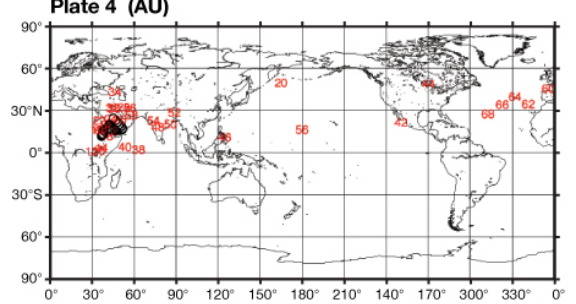

Plate 8 (IN)

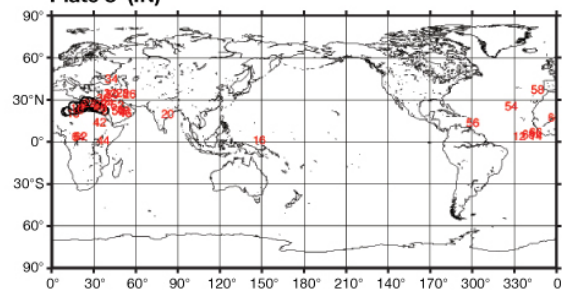

Plate 10 (NA)

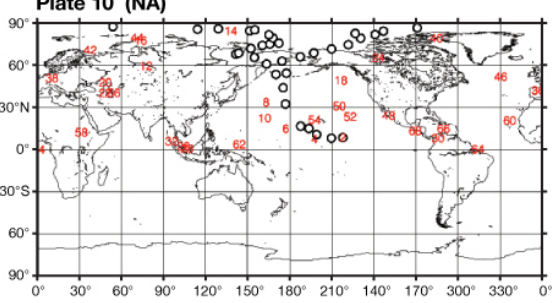

Plate 11 (NZ)

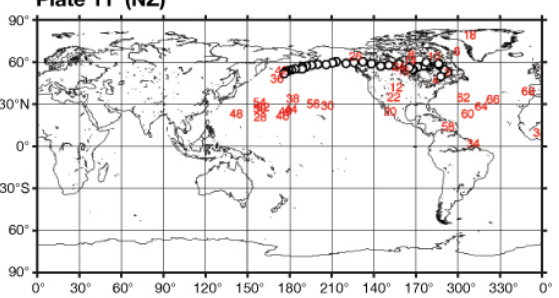

Plate 12 (PA)

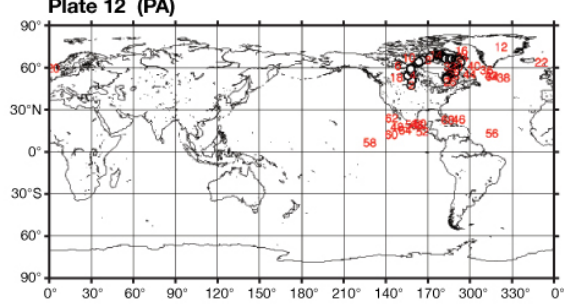

Plate 14 (SA)

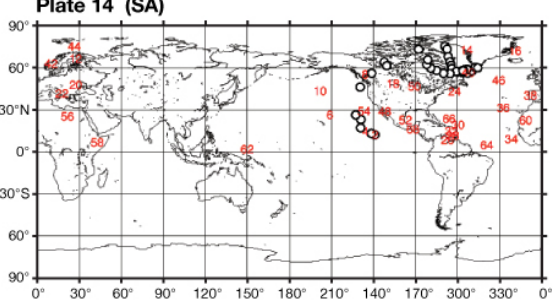

Fig. 11. Plots of NOIT Euler and stage pole locations (black circles and red numbers for million years, respectively).

been very good first approximations for analyzing plate tectonics. Although the plate acceleration values are very low, in geologic history it is Impulse (force times time) that produces deformations of the Earth's surface, such as subsidence of basins and mountain building. Impulse equals change of momentum, and the same change of momentum can be brought about by a violent massive blow of short duration (as in an asteroid or planetismal impact), or by a much smaller force acting over millions of years.

\section{Plate tectonics and conservation of angular momentum}

The exceedingly low acceleration/deceleration rates for the Earths tectonic plates clarifies why the early "no net torque" or "dynamical equilibrium" assumptions for global plate reconstructions provided reasonable assessments of the rela- tive magnitudes for possible driving forces (Morgan, 1973; Soloman and Sleep, 1974; Forsyth and Uyeda, 1975; and Chapple and Tullis, 1977). This is also why the concept of large-scale mantle convection cells transporting the overriding plates at constant velocities over extended time periods seemed so reasonable. However, the velocity and acceleration data shown in Fig. 13 (4448), and those in the Supplementary Material (S2, http://www.electronic-earth.net/5/ 1/2010/ee-5-1-2010-supplement.zip), demonstrate that the plates do accelerate and decelerate. Therefore, plate tectonics is governed by conservation of angular momentum. Thus, if the angular momentum of one plate decreases, the angular momentum of some other plates must increase to conserve a constant global angular momentum. There was, of course, the possibility that compensating momentum changes might occur in the underlying mantle, so a global plate tectonic test was needed. 
4448
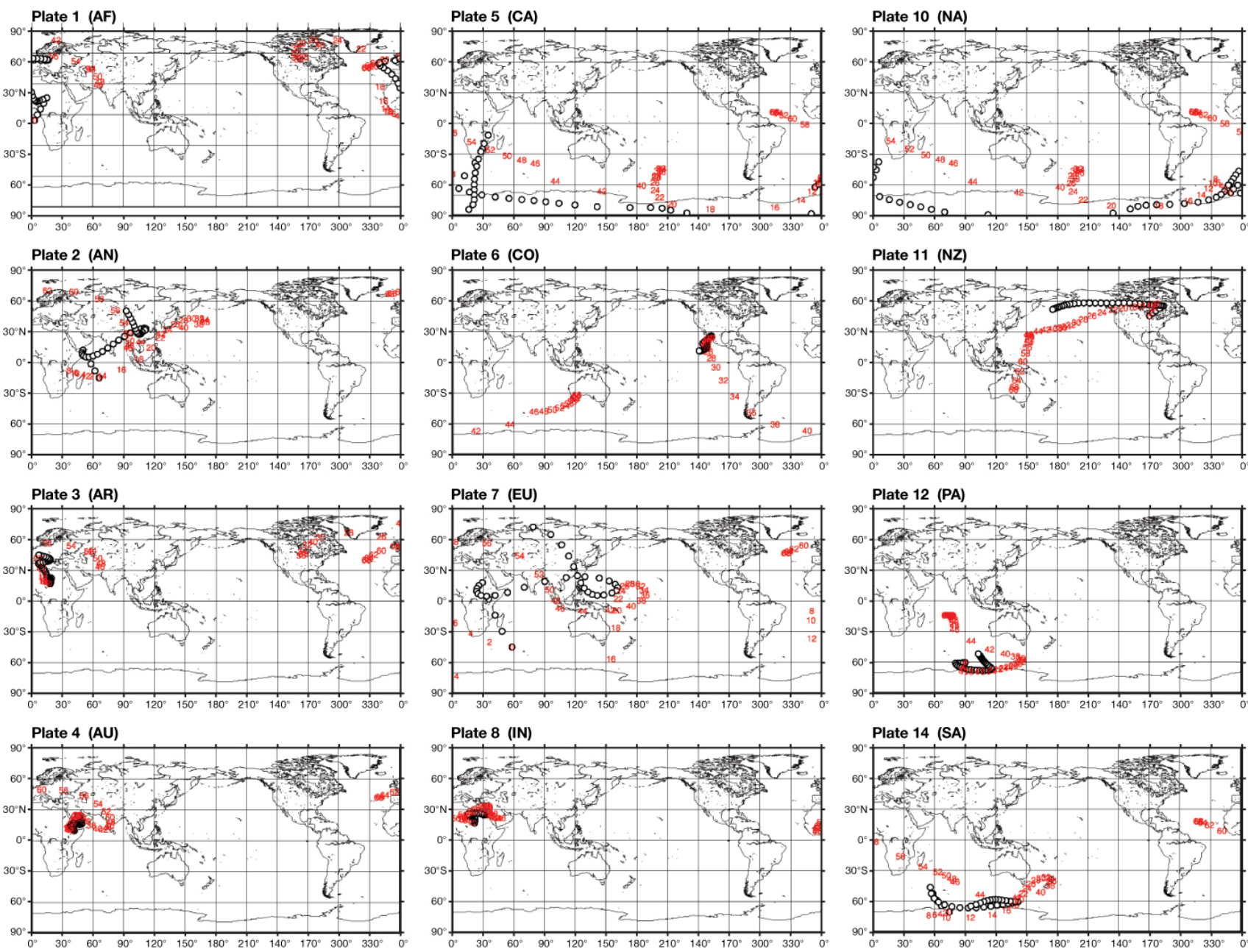

Fig. 12. Plots of 4448 Euler and stage pole locations (black circles and red numbers for million years, respectively).

To test how well our quaternion filtered plate data for 12 plates, at $2 \mathrm{Myr}$ intervals, might demonstrate such a global plate conservation of angular momentum, the following steps were taken:

1. A 1-degree global latitude $(-90$ to +90$)$ and longitude (0 to 259) grid was generated (area of each cell varies as a function of latitude), and files of 1-degree spaced data were produced for each plate at zero Myr (the present time).

2. A Perl script was written to aid consistent processing of 12 plates through steps at 2 Myr intervals, from 68 to $0 \mathrm{Myr}$, for processing, listing, graphic plotting, display, and printing of intermediate and combined final results. The processing was done initially on an SGI Indigo computer with IRIX operating system, and later on a PC computer running Cygwin under Microsoft Windows 2000Pro or XP operating systems. Each plate grid point normally comprised 15 binary values, but for some steps, ASCII files with fewer variables sufficed. The Perl script aided in combining operations utilizing Fortran 77, C, C++, GMT scripts, awk, sed, cc, cp, ls -1, and Enscript commands.

3. Global free-air gravity anomaly data (Bowin, 2000; Sandwell and Smith, 1997) demonstrate that most of the Earth's surface is within 40 milligals of zero, and hence is in isostatic equilibrium. Following Hess (1960, Fig. 2) I adopted $11775 \mathrm{~kg}$ as the mass of a $40 \mathrm{~km}$ thick column, $1 \mathrm{~cm}^{2}$ of lithosphere for a mean isostatic Earth column.

4. Calculation of each plates's 1-deg cell moment of inertia assuming its lithospheric mass $\left(11775 \mathrm{~kg} \mathrm{~m} / \mathrm{cm}^{2}\right)$ lies at $75 \mathrm{~km}$ depth, the mid point of a $150 \mathrm{~km}$ thick lithosphere. I interpret the decrease in relief away from 
Plate 12 (PA)
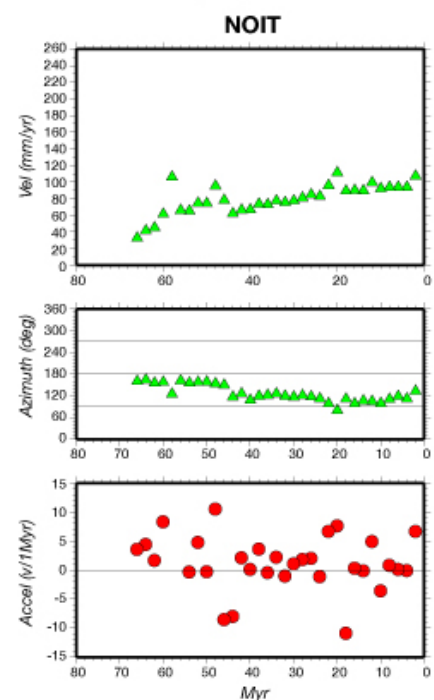

Plate 4 (AU)
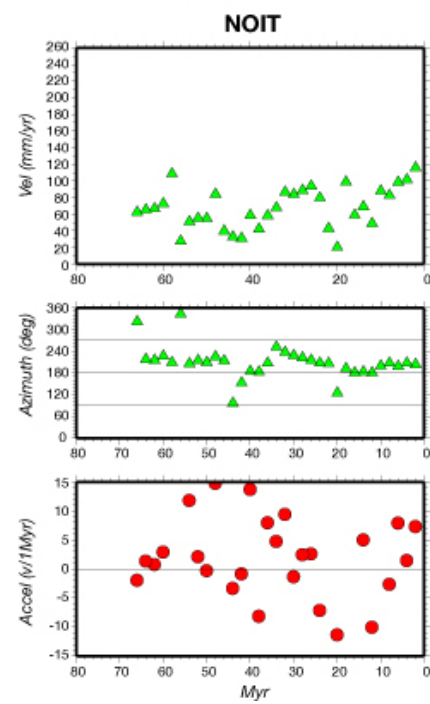
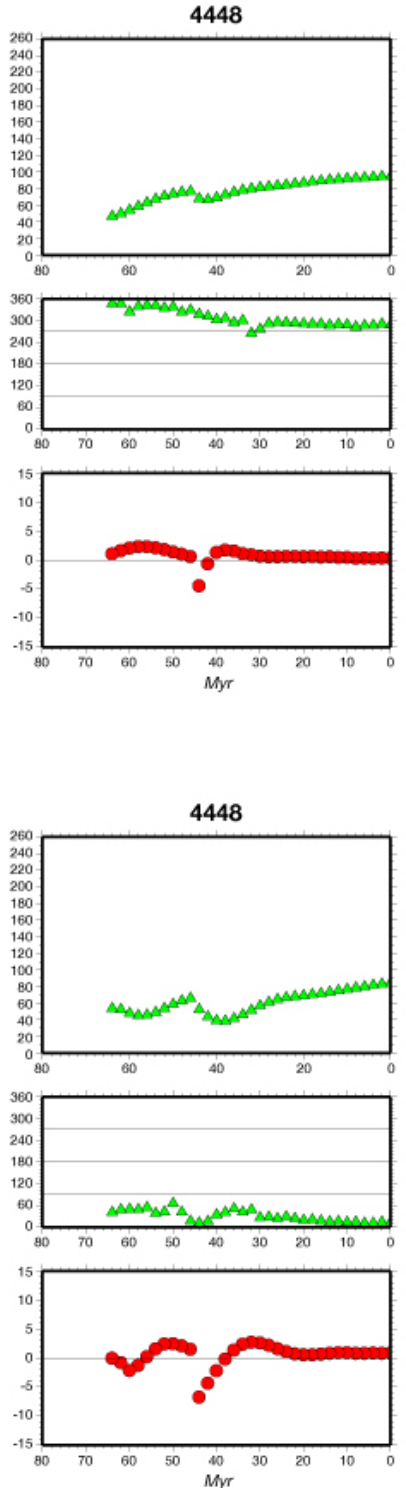

Plate 11 (NZ)
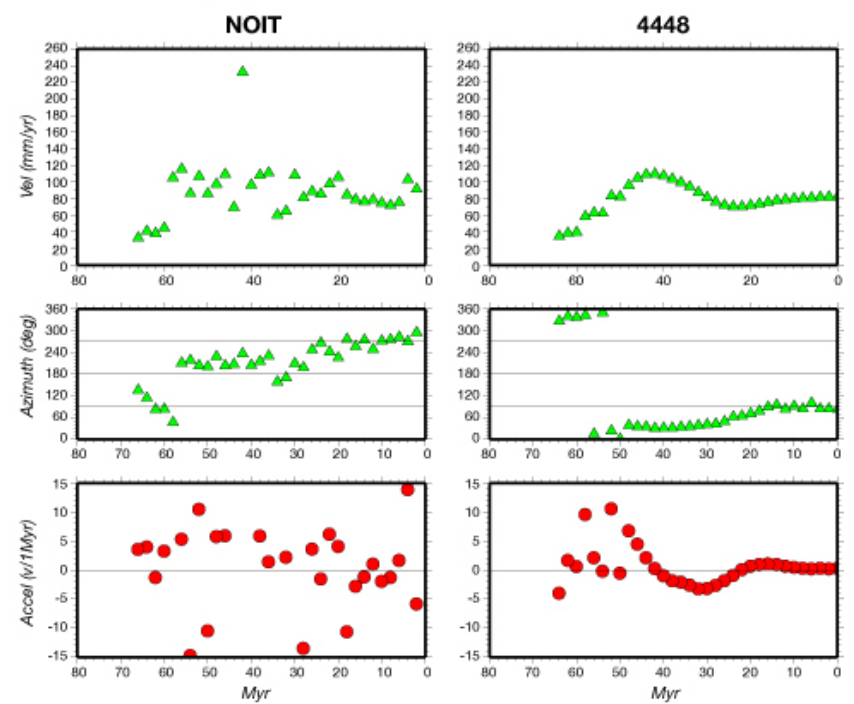

Plate 1 (AF)
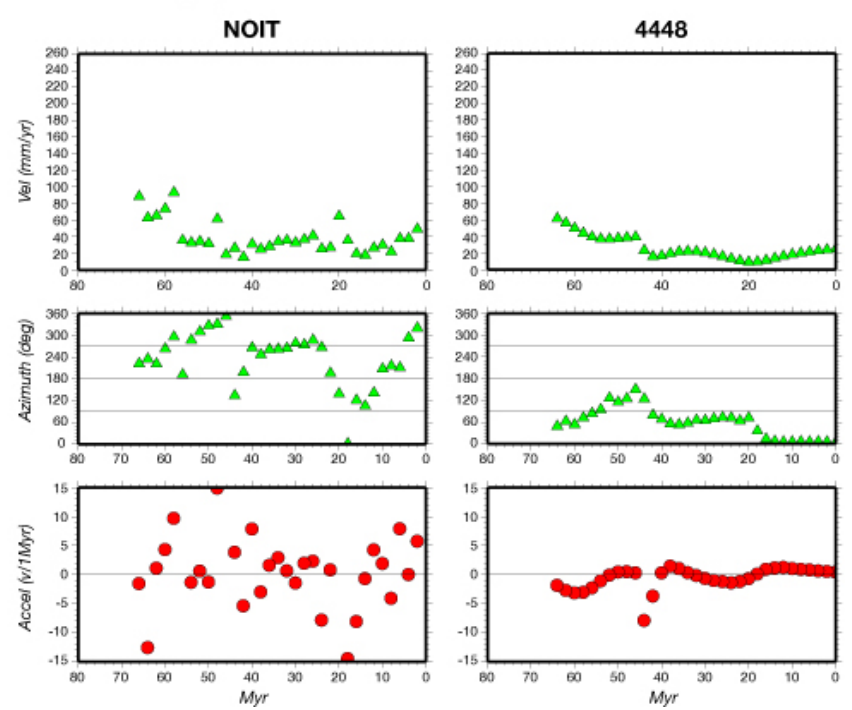

Fig. 13. Maximum velocity (mm/a), azimuth (degrees), acceleration (mm/yr/Myr) for NOIT and 4448, for plates 12 (PA), 11 (NZ), 4 (AU), 1 (AF) for 68-0 Myr.

the Mid Atlantic Ridge spreading center to be a consequence of thermal cooling, not a change of mass. This assumption is supported by the fact that almost everywhere, oceanic free-air gravity anomalies are within 40 milliGals (or less) of zero, and hence that the ocean lithosphere is in isostatic equilibrium. That is why I assumed a constant thickness (and mass) for all plates in the calculations. Similarly, that is why I reject a "ridge push" as a legitimate force.

5. Summing 1-deg cell moment of inertia contributions to obtain each plate's angular momentum at $2 \mathrm{Myr}$ intervals. Results for different mass and lithosphere thick- ness assumptions can be estimated by multiplying these estimated angular momentum values by a scaling factor to account for differing assumptions.

6. Sum estimates of plate angular momentums for all plates at each $2 \mathrm{Myr}$ interval. For these initial estimates, plates 9 (Juan de Fuca) and plate 13 (Philippine), and the Scotia plate were left unprocessed because of limited age rotation data.

7. The angular momentum of each plate, at $2 \mathrm{Myr}$ intervals, was calculated about each plate's stage pole axis, and the xyz components were calculated. Then at each 


\section{Angular Momentum - 4448}
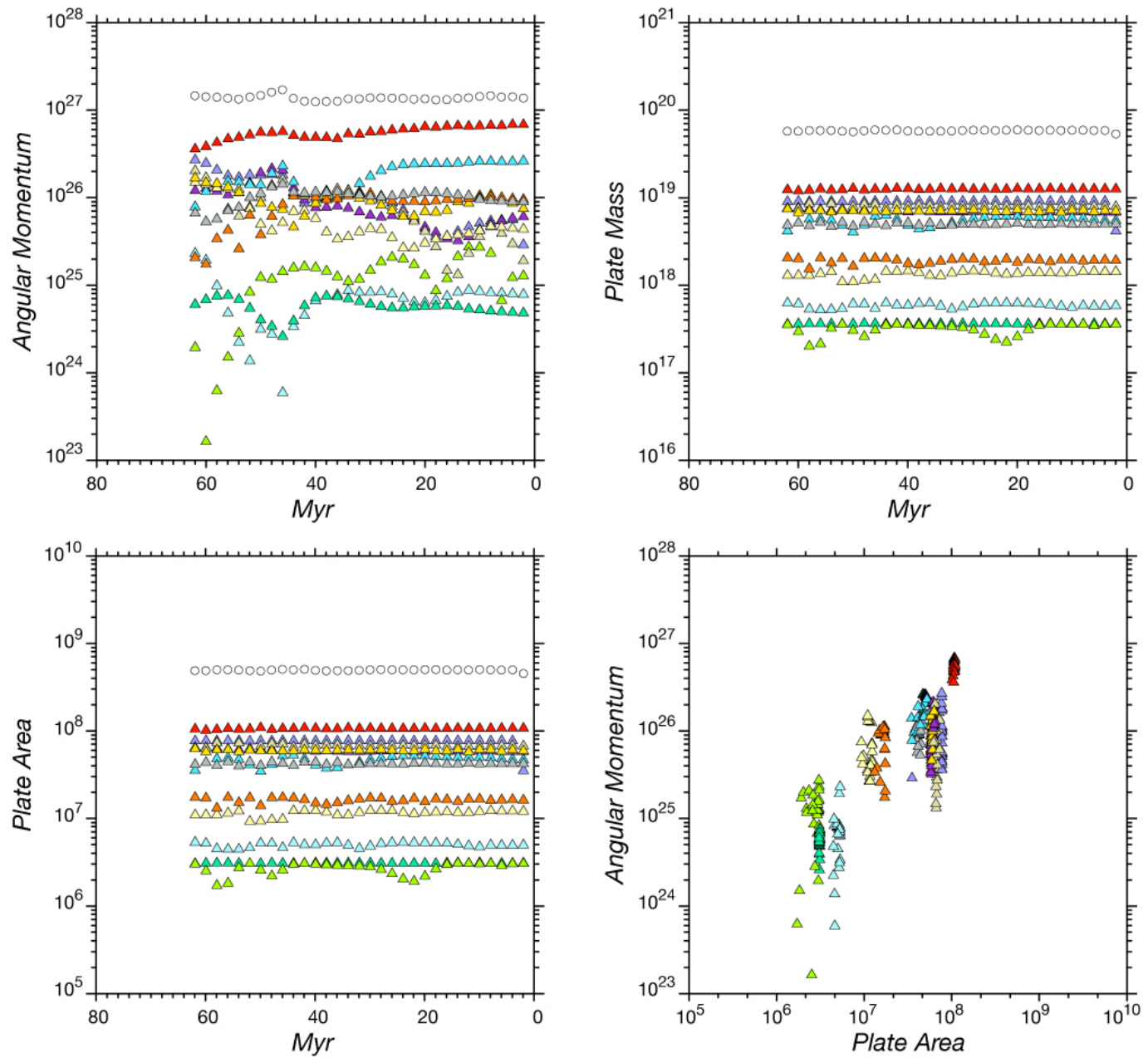

Fig. 14. Angular momentum, plate mass, plate area and angular momentum vs. plate area for the 4448 filtered data for $62-0$ Myr. Color ID for plates: af (dark grey), an (dark blue), ar (light blue), au (blue), ca (dark green), co (yellow green), eu (light yellow), in (pale yellow), na (dark yellow), nz (orange), pa (red), and sa (light gray).

2 Myr time, those xyz components for each plate were added together to obtain a "total" xyz for the total angular momentum axis, which varies in location with time, because "no-net-torque" does NOT apply to plate tectonics, and that is why plate motions migrate. I have come to the assumption that the plate motions (velocity and acceleration/deceleration) are independent of the rotation of the Earth.

8. The angular momentum history $\left(\mathrm{kg} \mathrm{m}^{2} \mathrm{~s}^{-1}\right)$ for the 4448 quaternion filtered data (1024 iterations) is shown in Fig. 14. Note the rather constant values for the total angular momentum (uncolored circles) from all 12 plates. This is, therefore, confirmation that plate tectonics conserves angular momentum. Also included are plots of plate area $\left(\mathrm{km}^{2}\right)$, estimated plate mass $(\mathrm{kg} \mathrm{m})$, and angular momentum $\left(\mathrm{kg}^{2} \mathrm{~s}^{-1}\right)$ vs. plate area. The last plot was made to examine any correlation between angular momentum and plate area. The maximum angular momentum values attained vary linearly as $10^{18}$ times the plate area. Table 2 summarizes the plate area and angular momentum results for the filtered 4448 data at 0 Myr.

The data in Table 2 shows that at $0 \mathrm{Myr}$, the Pacific (the largest plate) has $21 \%$ of the Earth's surface area, presently comprises $49 \%$ of plate tectonics' total angular momentum, whereas the second largest plate, Africa, with $15 \%$ area has only about $4 \%$ of the total plate tectonic angular momentum. Figure 14, however, indicates that at $62 \mathrm{Myr}$, both the Pacific and Africa plates then had much closer values of angular momentum (Pacific at $26 \%$ and Africa at $19 \%$ ), their combined total of $45 \%$ is lower than that of the Pacific plate alone at 0 Myr. This example helps illustrate the constant shifting of 
Table 2. Summary of plate area and angular momentum values and their percentage contributions for the 4448 filtered data at 0 Myr.

\begin{tabular}{cccccc}
\hline$\#$ & Plate Name & $\begin{array}{c}\text { Area } \\
\left(\mathrm{km}^{2}\right)\end{array}$ & $\%$ Total area & $\begin{array}{c}\text { Angular Momentum } \\
\left(\mathrm{kg} \mathrm{m}^{2} \mathrm{~s}^{-1}\right)\end{array}$ & $\begin{array}{c}\% \text { Total Angular Momentum } \\
(1.3951 \mathrm{E}+27)\end{array}$ \\
\hline 1 & af & $0.77173 \mathrm{E}+08$ & $15,12573 \%$ & $0.58020 \mathrm{E}+26$ & $4.15927 \%$ \\
2 & an & $0.57979 \mathrm{E}+08$ & $11.36199 \%$ & $0.64633 \mathrm{E}+26$ & $4.63286 \%$ \\
3 & ar & $0.50078 \mathrm{E}+07$ & $0.981517 \%$ & $0.72817 \mathrm{E}+25$ & $0.52195 \%$ \\
4 & au & $0.47208 \mathrm{E}+08$ & $8.24758 \%$ & $0.26953 \mathrm{E}+27$ & $19.31976 \%$ \\
5 & ca & $0.30990 \mathrm{E}+07$ & $0.607399 \%$ & $0.47057 \mathrm{E}+25$ & $0.3373 \%$ \\
6 & co & $0.30247 \mathrm{E}+07$ & $0.592834 \%$ & $0.10320 \mathrm{E}+26$ & $0.73973 \%$ \\
7 & eu & $0.67316 \mathrm{E}+08$ & $13.19378 \%$ & $0.78757 \mathrm{E}+25$ & $0.56453 \%$ \\
8 & in & $0.12094 \mathrm{E}+08$ & $2.3704 \%$ & $0.41384 \mathrm{E}+26$ & $2.96638 \%$ \\
9 & jf & & & & $4.68253 \%$ \\
10 & na & $0.59553 \mathrm{E}+08$ & $11.67225 \%$ & $0.65326 \mathrm{E}+26$ & $6.57989 \%$ \\
11 & nz & $0.16339 \mathrm{E}+08$ & $3.20241 \%$ & $0.91796 \mathrm{E}+26$ & $49.16493 \%$ \\
12 & pa & $0.10719 \mathrm{E}+09$ & $21.009 \%$ & $0.68590 \mathrm{E}+27$ & $6.7983 \%$ \\
13 & ph & & & & $100.46743 \%$ \\
14 & sa & $0.42519 \mathrm{E}+08$ & $8.33363 \%$ & $0.88053 \mathrm{E}+26$ & Total \\
\hline
\end{tabular}

Surface area of sphere $=4 \pi \cdot 6371 \mathrm{~km}^{2}=5.1021 \mathrm{E}+08 \mathrm{~km}^{2}$

stage pole locations and rotation rates involved in the conservation of plate tectonic angular momentum.

In the plate area vs. Myr plot of Fig. 14 for the 4448 filtered data, the plate areas, from greatest to least, are: pa $\left(1.1^{+08} \mathrm{~km}^{2}\right)$, af $\left(0.77^{+08} \mathrm{~km}^{2}\right)$, eu $\left(0.67^{+08} \mathrm{~km}^{2}\right)$, na $\left(0.60^{+08} \mathrm{~km}^{2}\right)$, an $\left(0.58^{+08} \mathrm{~km}^{2}\right)$, au $\left(0.47^{+08} \mathrm{~km}^{2}\right)$, sa $\left(0.43^{+08} \mathrm{~km}^{2}\right)$, nz $\left(0.16^{+08} \mathrm{~km}^{2}\right)$, in $\left(0.12^{+08} \mathrm{~km}^{2}\right)$, ar $\left(0.05^{+08} \mathrm{~km}^{2}\right)$, ca $\left(0.031^{+08} \mathrm{~km}^{2}\right)$, and co $\left(0.030^{+08} \mathrm{~km}^{2}\right)$. The order of these areas in $\mathrm{km}^{2}$ differs from that in Bird (2002, Fig. 19 in steradian) in that the eu (3rd) and an (5th) positions are interchanged. This is probably due to the coarser grid interval $\left(1 \mathrm{deg}^{2}\right)$ used in this study.

\section{Global plate velocity map images}

The computations of plate angular momentums referred to above utilized 1-deg grid files (for each plate, at each $2 \mathrm{Myr}$ time) of stage pole velocity and azimuth at each grid point For each $2 \mathrm{Myr}$ age, the individual plate velocity grid point values were added to an empty world 1-deg data grid in the following plate order: $1,2,3,10,14,7,12,4,8,11,6$. If a plate velocity value had previously been assigned to that grid cell, then the new velocity value would not displace the prior one. This procedure reduced the number of "black spots" that result from contour lines around errant velocity values. A different order for adding plate data to the blank grid might improve the display for the $62-48 \mathrm{Myr}$ maps. White numbers are plotted at the location of each plate's stage pole for that Myr plot. A red star plotted at the location of the total angular momentum pole is also plotted for the 62 to $0 \mathrm{Myr}$ plots. Again, data for plates 9 (Juan de Fuca), and 13 (Philippine), as well as the Scotia Sea, were not included Plate 6 (Cocos) was included, but since its data range is only 0 to $26 \mathrm{Myr}$, the older results are not reliable.

Figure 15 shows examples of global plate stage pole velocity maps with two-segment (4448, 1024 iterations), at 0 , 10, 20, 30, 40, 44, 46, 50, and 60 Myr. The velocity color scale is in $\mathrm{mm} / \mathrm{yr}$. The red stars identify the locations of the axis of total plate tectonic angular momentum for the twelve plates processed. (Note that the PDF figures in this paper, if downloaded to the viewer's computer, can then be enlarged or reduced as desired.) At $46 \mathrm{Myr}$ the Pacific plate attains its greatest maximum velocity along the Emperor Seamount chain direction, and at $42 \mathrm{Myr}$ the Pacific plate has its smallest maximum velocity value along the Hawaiian seamount chain direction (see Fig. 13 or the Supplementary Material (S2, Plate 12 (PA), http://www.electronic-earth.net/5/1/2010/ ee-5-1-2010-supplement.zip)).

These stage pole velocity maps, at $2 \mathrm{Myr}$ intervals, from the 4448 quaternion filtering (using 1024 iterations for the smoothing process), were assembled into a QuickTime movie (4448_wr_4a.mov in the Supplementary Material (S3, supplementzip)). Future experiments with different plate order assemblages, and with modified quaternion filter time boundaries, may later provide a better quality movie presentation.

Particularly striking at $0 \mathrm{Myr}$ in Fig. 15 (and in the 4448 QuickTime movie), are the high maximum velocities of both the Pacific and Australian plates, and the fact that their maximum velocity vectors (green arrows), hence their plate torques, are directed at nearly 90 degrees to each other. Further, the eastern edge of the Australian plate interlocks with 


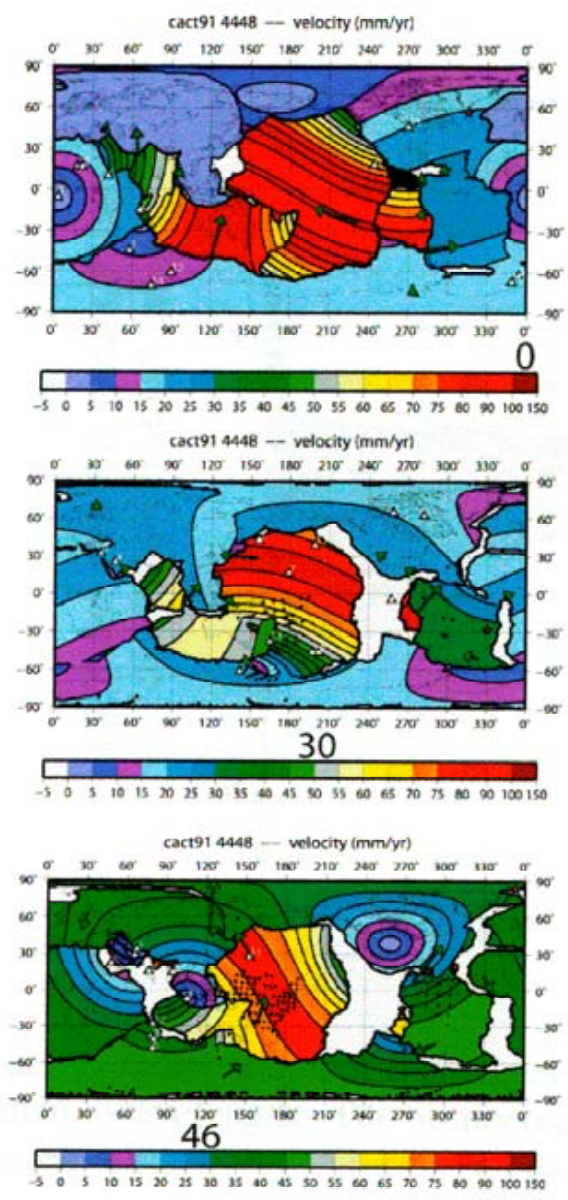

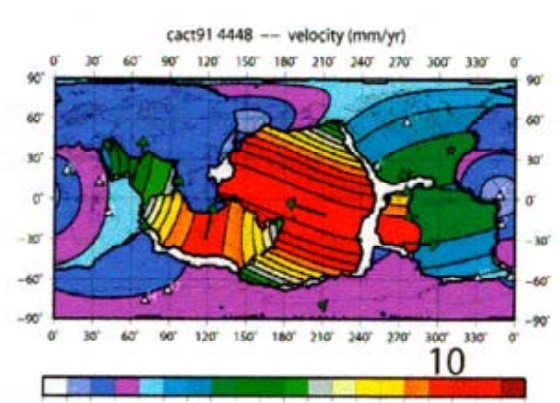
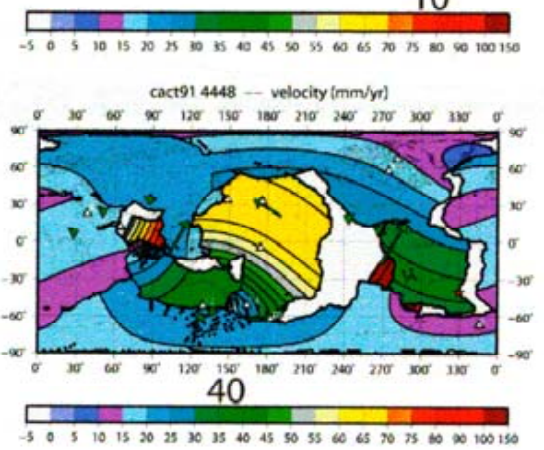

cact91 4448 - velocity $(\mathrm{mm} / \mathrm{yr})$

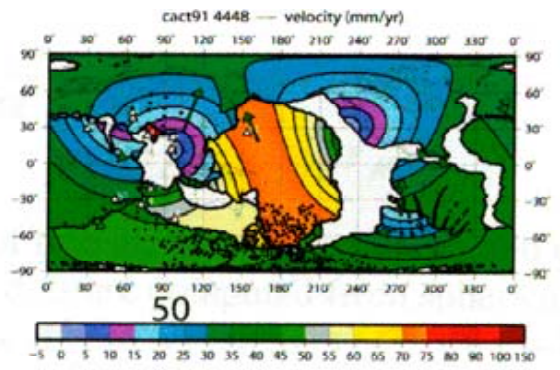

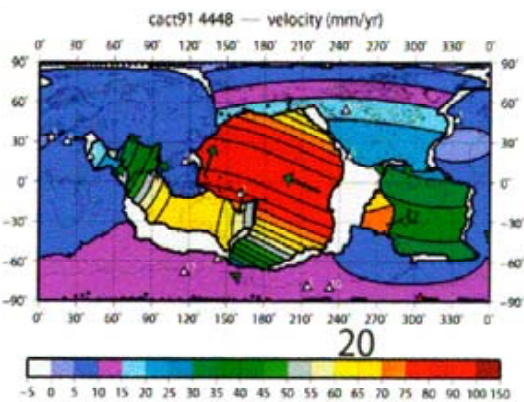

cact91 4448 - velocity (mmyyt)

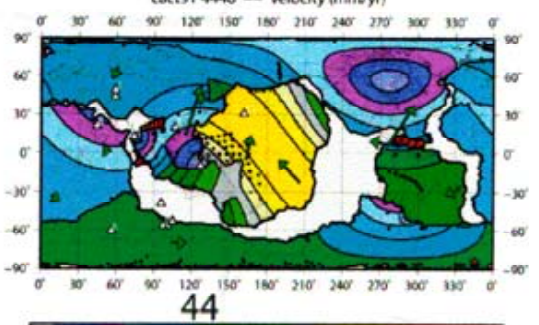

44

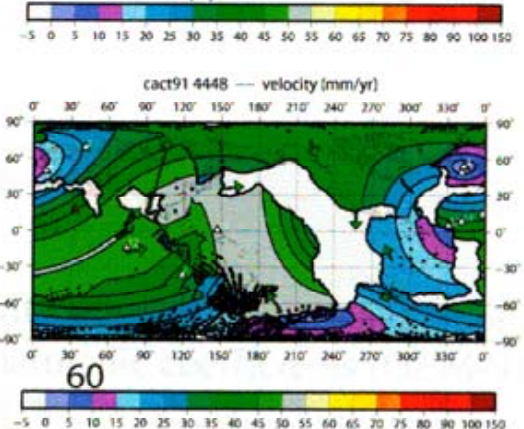

Fig. 15. Global plate velocity maps at 10 million year intervals, with maps at $44 \mathrm{Myr}$ (in transition to Hawaiian Seamount trend) and $46 \mathrm{Myr}$ (at end of Emperor Seamount trend) added. Velocity color scale is in $\mathrm{mm} / \mathrm{yr}$. White numbers indicate location of stage pole for the plate number. Red star shows location of axis for total angular momentum. The tails of the green arrows are at the latitude and longitude of each plate's maximum velocity value. The green arrow head shows the direction of the maximum velocity vector, and the longer its length, the greater its' velocity (mm/yr).

the Pacific plate as if it were a jigsaw puzzle piece. The $10,20,30$ and $40 \mathrm{Myr}$ velocity maps in the same figure also demonstrate this interlocking relationship, and with both plates having maximum velocities that increase with time towards the present age. During this 40 to $0 \mathrm{Myr}$ time interval the Pacific plate moved westward (subducting at the TongaKermadec trench as well as the Yap, Marianna, Izu-Bonin, Japan, and Kurile trenches), with the Australian plate moving northward (subducting at the Indonesian arc). This geometrically interlocked pattern of the pacific plate moving westward, with the Australian plate moving northward might be explained as having grown that way after spreading in the Tasman Sea ceased, and the oceanic region to the east became part of the Australian plate. A far more complex development pattern for this region has been put forward by Hall (2000) and shown by maps for the interval 40-5 Myr. In his abstract he states that his model is over-simplified and new models will inevitably be more complex However, I suggest that the detailed complexity here, may have a simpler explanation.

The relations just described suggest that the complex of opposing thrust faults (possibly with oblique slip), and intervening small spreading centers, volcanic island arcs, and transform faults along the northern border of the Australian plate between the Banda arc and north end of the Tonga trench, comprise an evolving system that collectively performs the role of a complex "transform fault zone boundary" between the Pacific plate moving westward, and the Australian plate moving northward. The "transform fault zone boundary" complex comprises a wedge zone of two thrust faults, a southern one dipping northward, extending from the deformed belt of northern New Guinea eastward to the north end of the Tonga subduction zone (Exxon, 1985). Within this wedge of opposing thrust and subduction faults are various spreading centers, transform faults, and narrow island chains (such as Vanuatu and Solomons). 
Such an interlocked pattern of absolute plate motions at near 90 degrees to each other is taken as strong evidence against prior interpretations that large thermally driven "roller" convection cells drive continental drift and plate tectonics. Thus, I conclude that large "roller" convection cells have not been active in the Earth's mantle the past $42 \mathrm{Myr}$, if ever. Instead, Plate tectonics is interpreted to be driven by sinking positive mass anomalies in the upper lower mantle produced by phase changes to denser minerals in subducted lithosphere. "Hotspot" plume sites are presumed to result from the rising of lower density material rising from deep mantle sources, most likely near the core mantle boundary. See Garnero and McNamara (2008) for a recent review of the possible properties, and uncertainties, of the D" layer above the CMB, and of plume origination sites.

\section{Results and conclusions}

1. This paper documents that the Earth's tectonic plates have undergone acceleration and deceleration during the past 62 million years. Further, my estimates of the Earth's total plate tectonic angular momentum support, during this time interval, my hypothesis that the physical law of conservation of angular momentum is obeyed by the global plate system. The very slow accelerations (mm/yr/Myr) of plate tectonics has only recently become definitive because of the geometric solution for the Euler pole history of the Pacific Plate developed by Harada and Hamano (2000), and the development of an iterative ability to smooth filter a time series of Euler poles by Bowin and Kuiper (2005).

2. A particularly striking change in angular momentum for the Pacific plate occurred near $46 \mathrm{Myr}$ when its northward acceleration towards the Aleutian Arc subduction zone (along the direction of the Emperor Seamount chain) slowed, and changed to a slower and more westerly motion toward the Philippine and Japanese subduction zones (along the direction of the Hawaiian Seamount chain). Concomitantly, the wedge-shaped spreading in the Tasman Sea ceased, and the Australian Plate renewed its subduction beneath the Indonesian Island Arc which continues to the present day. Thus the migration of a pattern of opening in the Indian Ocean noted by Bowin (1974), and more recently by Whittaker et al. (2007), has been a consequence of plate tectonic conservation of angular momentum.

3. The geometrically interlocked pattern of the pacific plate moving westward (subducting at the TongaKermadec trench, as well as the Yap, Marianna, IzuBonin, Japan, and Kurile trenches), with the Australian plate moving northward (subducting at the Indonesian Arc) is explained: it grew that way.
4. Such an interlocked pattern of plate motions at near 90 degrees to each other, is taken as strong evidence that prior interpretations of large thermally driven "roller" convection cells driving continental drift and plate tectonics, have not been active in the Earth's mantle the past $42 \mathrm{Myr}$, if ever.

5. Wedge-shaped spreading segments are like propagating cracks, and result from adjustments to conserve plate tectonic angular momentum.

6. Spreading ridge axes are passive (responsive) features, not drivers. Asymmetries in spreading rates, ridge jumps, and double-ridge segments may result from differing torques on the opposing sides.

7. The Gakkel Ridge, SW Indian Ridge, and the MidAtlantic ridge (Dick et al., 2003), where undeformed peridotite (non-volcanic crust) is exposed on the seafloor are taken as further evidence of the passive (reactive) nature of spreading sites.

8. Extrapolating from the Pacific plate velocity curve (Fig. 13, plate 12), the Pacific Plate might have had a zero velocity about 90-120 Myr ago. Engebretson et al. (1986, p. 9) suggested evidence that the Pacific Plate had little or no absolute motion prior to the mid-Early Cretaceous time. Their maps (their Fig. 3) do not depict Pacific subduction zones until 80 Myr when a Kula plate is shown.

9. If the Pacific plate (or any other plate) did have zero angular momentum in the 80-120 Myr range, or any other time range, that would not indicate that plate tectonics started then, but that other plates were then in motion. Prior to $\sim 130 \mathrm{Myr}$, the age of the oldest hotspot track (Torsvik et al., 2008), past plate reconstructions must rely upon remnant paleomagnetic inclinations and geologic evidence of former subduction zone locations.

10. How, when, or why plate tectonics may have started, or how plate subuction is initiated, is not being answered here. I infer that 'conservation of angular momentum' must also have applied during the Mesozoic and Paleozoic periods. Hence I cannot concur with the arguments of Silver and Behn (2008) that plate tectonics may have stopped during past times because continent-continent collision might eliminate most of Earth's subduction zones. Both Stern (2008) and Condie and Kruner (2008) conclude that the modern era of global plate tectonics began in Neoproterozoic time $(<1.0 \mathrm{Ga}$ ago $)$, but that prior to that time, perhaps by $3.0 \mathrm{Ga}$, or even earlier, it may have began locally and may have progressively became more widespread from the early to late Archean. 
11. Very large massive asteroid or planetesmal impacts upon the Earth could be a mechanism for initiating or altering the total magnitude of plate tectonic angular momentum.

12. The estimated acceleration values found in this study are about $10^{-8}$ times smaller in magnitude than typical plate velocities. This is why prior no-net-torque solutions have been very good first approximations for analyzing plate tectonics. Although the plate acceleration values are very low, in geologic history it is impulse (force times time) that produces subsidence of basins and mountain building. Impulse equals change of momentum, and the same change of momentum can be brought about by a violent massive blow of short duration, or by a small force acting over millions of years.

13. The apparent beginning of Pacific plate deceleration at about 56 Myr (see Fig. 13, and the Supplementary Material (S2, Plate 12(PA), http://www.electronic-earth. net/5/1/2010/ee-5-1-2010-supplement.zip)) may reflect a beginning of a period of crustal deformation in Alaska north of the Aleutian Island Arc. Future examinations of possible correlations of stage pole location variations (Fig. 12) and plate deceleration episodes (Supplementary Material (S2, http://www.electronic-earth.net/5/1/ 2010/ee-5-1-2010-supplement.zip)) with timings and magnitudes of crustal deformations, will be interesting and hopefully informative.

Acknowledgements. I wish to express my appreciation to my deceased parents, and to Harry Hess, for their encouragement and example to be unafraid to travel new paths. I thank Gary Acton for providing a copy of mpfin.f written by Jason Morgan, and also providing Acton's digital compilation of published plate-pair rotation poles. The analysis capability demonstrated here is indebted to Harry Kuiper for developing the quaternion filtering routine. In this endeavor, as an Emeritus scientist with limited financial research support, I want to especially thank the following for helping me in solving a variety of problems in developing and maintaining functioning computer hardware and software systems: Julie Allen, Warren Sass, Roger Goldsmith, Christine Hammond, John Krauspe, Randy Manchester, Eric Cunningham, Tom Bolmer, Stanley Hammond, Mark Jones, Deborah Shaffer, and Mark Hickey. I also benefited over the years from mathematical discussions with Brechner Owens. Ann Devenish assisted in reference retrievals. Jack Cook helped assemble and format convert several manuscript illustrations, and Christina Cuellar, Kelly Servant, and Lynn Stellrecht aided final manuscript preparation. John Pierce and John Andelin provided very helpful edit comments, as did Ben Horner-Johnson and two anonymous reviewers. Natascha Töpfer at Copernicus Publications assisted an efficient submission process. I thank the Woods Hole Oceanographic Institution for annual Emeritus research support, and the Geology and Geophysics Department Chairmen, Susan Humphris and Maurice Tivey, for supporting manuscript preparation.

Edited by: J. Smit

\section{References}

Andrewa, D. L.,Gordon, R. G., and Horner-Johnson, B. C.: Uncertainties in Plate reconstructions relative to the hotsoits, Pacifichotspot rotations and uncertainties for the past 68 million yeara, J. Int., 166, 939-951, 2006.

Bercovici, D., Ricard, Y., and Richards, M. A.: The relation between mantle dynamics and plate tectonics: a primer, The history and dynamics of global plate motions, Geophys. Monog., 121, 5-46, 2000.

Bird, P.: An updated digital model of plate boundaries, Geochem. Geophys. Geosyst., 4, 3, 1027, 2003.

Bernstein, R. and Bowin, C. O.: Real-Time Digital Computer Acquisition and Computation of Gravity Data at Sea, IEEE T. Geosci. Elect., GE-1, 1, 2-10, 1963.

Bowin, C.: Migration of a Pattern of Plate Motion, Earth Planet. Sci. Lett., 21, 400-404, 1974.

Bowin, C.: Depth of Principal Mass Anomalies Contributing to the Earth's Geoidal Undulations and Gravity Anomalies, Mar. Geod., 7, 61-100, 1983.

Bowin, C.: Topography at the Core-Mantle Boundary, Geophys. Res. Lett., 13, 13, 1513-1516, 1986.

Bowin, C.: Earth's Gravity Field and Plate Tectonics, Tectonophysics issue with contributions to Texas A\&M Geodynamics Silver Anniversary Symposium, 187, 69-89, 1991.

Bowin, C.: Mass Anomalies of Earth, Venus and Mars: Initial Estimates, in: Gravity, Geoid and Marine Geodesy, International Symposium Tokyo, edited by: Segawa, J., Fujimoto, H., and Okubo, S., Springer-Verlag, 117, 257-264, 1997.

Bowin, C.: Mass anomaly structure of the Earth, Rev. Geophys., 38, 3, 355-387A, 2000.

Bowin, C.: Assessing Why Plates Move, EOS Trans. Am. Geophys. U., 85(17) (J. Assem. Suppl., Abstract T33A-05), 2004.

Bowin, C., Lu, R. S., Lee, C. S., and Schouten, H.: Plate convergence and accretion in Taiwan-Luzon region, AAPG Bulletin, 62, 9, 1645-1672, 1978.

Bowin, C., Scheer, E., and Smith, W.: Depth estimates from ratios of gravity, geoid, and gravity gradient anomalies, Geophysics, 51(1), 123-136, 1986.

Bowin, C. and Kuiper, H.: Resolving accelerations of Earth's Plate tectonics, Poster at AGU Meeting Toronto, Canada, Abstract No. \#T43C-01, viewable at: ftp://ftp.whoi.edu/pub/users/ cbowin, 2005.

Cande, S. C. and Kent, D. V.: Revised calibration of the geomagnetic polarity timescale for late Cretaceous and Cenozoic, J. Geophys. Res., 100, 6093-6095, 1995.

Chapple, W. M. and Tullis, T. E.: Evaluation of the forces that drive the plates, J. Geopphys. Res., 82, 14, 1967-1984, 1977.

Condie, K. C. and Kroner, A.: When did plate tectonics begin? Evidence from the geologic record, in: When did plate tectonics begin on planet Earth?, edited by: Condie, K. C. and Pease, V., Geol. Soc. Am. Spec., Paper 440, 281-294, 2008.

Conrad, C. P. and Lithgow-Bertelloni, C.: How Mantle Slabs Drive Plate Tectonics, Science, 298, 207-209, 2002.

Dick, H. J. B., Lin, J., and Schouten, H.: An ultraslow-spreading class of ocean ridge, Nature, 246, 405-412, 2003.

Dietz, R. S.: Continent and ocean basin evolution by spreading of the sea floor, Nature, 190, 854-857, 1961a.

Dietz, R. S.: The Speading Ocean Floor" Saturday Evening Post, 234 (21 October 1961) 34-35, 94-96, 1961b. 
Doglioni, C., Green, D. H., and Mongelli, F.: On the shallow origin of hotspolts and the westward drift of the lithosphere, Geol. Soc. Am. Spec., Paper 388, 735-749, 2005.

Engebretson, D. C., Cox, A., and Gordon, R. G.: Relaative motions between oceanic and continental plates in the Pacific basin, Geol. Soc. Am. Spec., Paper 206, 1-59, 1985.

Exxon: Tectonic map of the world, Exxon Production Research Company, 18 sheets, scale 1:10000000, prepared by the World Mapping Project as part of the tectonic map series of the world, 1985.

Forsyth, D. and Uyeda, S.: On the relative importance of the driving forces of plate motion, Geophys. J. R. Astr. Soc, 43, 163-200, 1975.

Garnero, E. J. and McNamara, A. K.: Structure and dynamics of the Earth's lower mantle, Science, 320, 626-628, 2008.

Gordon, R. G. and Jurdy, D. M.: Cenozoic global plate Motions, J. Geophys. Res., 91(B12) 12389-12406, 1986.

Gripp, A. E. and Gordon, R. G.: Current plate velocities relative to the hotspots incorporating the NUVEL-1 global plate motion model, Geophys. Res. Lett., 17, 8, 1109-1112, 1990.

Gripp, A. E. and Gordon, R. G.: Young tracks of hotspots and current plate velocities, Geophys. J. Int., 150, 321-361, 2002.

Hager, B. H. and O'Connell, R. J.: A simple global model of plate dynamics and mantle convection, J. Geophys. Res, 86(B6), 4843-4867, 1981.

Hager, B. H.: Subducted slab and the geoid: constrains/ts on mantle reology and flow, J. Geophys. Res., 89, 6003-6015, 1984.

Hager, B. H., Clayton, R.W., Richards, M. A., Comer, R. P., and Dziewonski, A. M.: Lower mantle heterogeneity, dynamic topography, and the geoid, Nature, 313, 541-545, 1985.

Hall, R.: Cenozoic geological and plate tectonic evolution of SE Asia and the SW Pacific: computer-based reconstructions, model and animations, J. Asian Earth Sciences, 20, 353-431, 2002.

Harada, Y. and Hamano, Y.: Recent progress on the plate motion relative to hotspots, in: The History and Dynamics of Global Plate Motions, Geophys. Mono., 121, 327-338, 2000.

Hess, H. H.: Preprint Evolution Ocean Basins, Princeton Univ. Dept. of Geology, 38 pp., scanned PDF copy viewable at: ftp://ftp.whoi.edu/pub/users/cbowin named copy_HH Hess_1990_evolution_ocean_basins.pdf, 1960.

Hess, H. H.: History of Ocean Basins. Evolution Ocean Basins, in: Petrologic Studies: A Volume in Honor of A. F. Buddington, edited by: Engle, A. E. J., James, H. L., and Leonard, B. F., Boulder, Colorado, Geological Society of America, 599-620, 1962.

Iaffaldano, G. and Bunge, H.-P.: Relating rapid plate motion variations to plate-boundary forces in global coupled models of the mantle/lithosphere system: Effects of topography and friction, Geophys. Tectonophysics, 74, 393-404, 2009.

Jin Shuanggen and Zhu Wenyao: Contemporary crustal motion and deformation of South America plate, Geo-Spacial Information Science, Wuhan University of Technology, 6, 2, 2003.

Jin Shuanggen and Zhu Wenyao: Tectonic motion characteristics of the Earth planet: from $80 \mathrm{MaBP}$ up to now, Sciene in China Ser. G Physics, Mechanics and Astronomy, 47, 3, 352-364, 2004.

King, S. D., Lowman, J. P., and Gable, C. W.: Episodic tectonic plate reorganizations driven by mantle convection, Earth Planet. Sci. Lett., 203, 1, 83-91, 2002.
Klootwijk, C., Gee, T. J. S., Peirce, J. W., and Smith, G. M.: Constraints on the India-Asia convergence: paleomagnetic results from Ninetyeast ridge, Chapter 39, in: Proceedings of the Ocean Drilling Program, Scientific Results, edited by: Weissel, J., Peirce, J., Taylor, E., Alt, J., et al., 121, 777-882, 1991.

Molnar, P. and Stock, J.: Relative motions of hotspots in the Pacific, Atlantic and Indian Oceans since late Cretaceous time, Nature, 327, 587-591, 1987.

Morgan, W. J.: Convection plumes in the lower mantle, Nature, 230, 42-43, 1971.

Morgan, W. J.: Deep mantle convection plumes in the lower mantle, Am. Assoc. Pet. Geol. Bull., 56, 203-213, 1972.

Morgan, W. J.: Plate motions and deep mantle convection, Geol. Soc. Am. Mem., 123, 7-22, 1973.

Norton, I. O.: Plate motions in the north Pacific; the 43 Ma nonevent, Tectonics, 14, 1080-1094, 1995.

Norton, I. O.: Global hotspot reference frames and plate motion, in: The History and Dynamics of Global Plate Motions, edited by: Richards, M. A., Gordon, R. G., and van der Hilst, R. D., AGU Geophysical Monograph, 121, 339-357, 2000.

Petronotis, K. E. and Gordon, R. G.: A Maastrichian paleomagnetic pole for the Pacific plate determined from a skewness analysis of marine magnetic anomaly 32, Geophys. J. Int., 139, 227-247, 1999.

Ricard, Y., Richards, M., Lithgow-Bertelloni, C., and Le Stuff, Y.: A geodynamical model of mantle density heterogeneity, J. Geophys. Res., 98(B12), 21895-21909, 1993

Sandwell, D. T. and Smith, W. H. F.: Marine gravity anomaly from Geosat and ERS 1 satellite altimetry, J. Geophys. Res., 102, 10039-10054, 1997.

Sharp, W. D. and Clague, D. A.: 50-Ma initiation of HawaiianEmperor bend records major change in Pacific plate motions, Science, 313, 1381-1284, 2006,

Silver, P. G. and Behn, M. D.: Intermittent Plate tectonics?, Science, 319, 85-88, 2008.

Soloman, S. C. and Sleep, N.: Some simple physical models for absolute plate motions, J. Geophys. Res., 79, 2557-2564, 1974.

Steinberger, B. and O'Connell, R. J.: Effects of mantle flow on hotspot motion, in: The History and Dynamics of Global Plate Motions, edited by: Richards, M. A., Gordon, R. G., and van der Hilst, R. D., AGU Geophysical Monograph, 121, 377-398, 2000.

Stern, R. J.: Modern-style plate tectonics began in Neoproterozoic time: An alternative interpretation of Earth's tectonic history, in: When did plate tectonics begin on planet Earth?, edited by: Condie, K. C. and Pease, V., Geol. Soc. Am. Spec., Paper 440, 265-280, 2008.

Tarduno, J. A.: On the motion of Hawaii and other mantle plumes, Chem Geol., 241, 234-247, 2007.

Tarduno, J. A., Duncan, R. A., Scholl, D. W., Cottrell, R. D., Steinberger, B., Thordarson, T., Kerr, B. C., Neal, C. R., Frey, F. A., Torii, M., and Carvallo, C.:The Emperor Seamounts: southward motion of the Hawaiian hotspot plume in Earth's mantle, Science, 301, 1064-1069, 2003.

Torsvik, T. H. R., Muller, D., and van der Voo, R.: Bernhard Steinberger, and Carmen Gaina, 2008, Global plate motion frames: toward a unified model, Rev. Geophys., 46, RG3004, 1-44, 2008. 
Tullis, T. E. and Chapple, W. M.: What makes the plates go, Eos, 54, 468, 1973.

Vine, F. J. and Matthews, D. H.: Magnetic anomalies over oceanic ridges, Nature, 199, 947-949, 1963.

Watts, A. B., Weissel, J. K., Duncen, R. A., and Larson, R. L.: Origin of the Louisville Ridge and its relationship to the Eltanin fracture zone system, J. Geophys. Res., 93(8), 3051-3077, 1988.

Wessel, P., Harada, Y., and Kroenke, L. W.: Toward a selfconsistent, high-resolution absolute plate motion model for the Pacific, Geochem. Geophys. Geosyst., 7, Q03L12, 2006.

Wessel, P. and Kroenke, L. W.:Reconciling late Neogene Pacific absolute and relative plate motion changes, Geochem. Geophys. Geosyst., 8, Q08001, 2007.
Whittaker, J. M.: Major Australian-Antarctic Plate reorganization at Hawaiian-Empereor bend time, Science, 318, 5847, 83-86, 2007.

Wilson, J. T.: A possible origin of the Hawaiian Islands, Can. J. Phys., 41, 863-870, 1963.

Wilson, J. T.: A new class of faults and their bearing on continental drift, Nature, 207, 343-347, 1965.

Wu Benjun, Conrad, C. P., Heurer, A., Lithgow-Berteloni, C., and Lallemand, S.: Reconcilling strong slab pull and weak plate bending: The plate motion constraint on the strength of mantje slabs, Earth Planet. Sci. Lett., 272, 1-2, 412-421, 2008. 